\title{
Thienopyridine derivatives versus aspirin for preventing stroke and other serious vascular events in high vascular risk patients (Review)
}

Sudlow CLM, Mason G, Maurice JB, Wedderburn CJ, Hankey GJ

Sudlow CLM, Mason G, Maurice JB, Wedderburn CJ, Hankey GJ.

Thienopyridine derivatives versus aspirin for preventing stroke and other serious vascular events in high vascular risk patients.

Cochrane Database of Systematic Reviews 2009, Issue 4. Art. No.: CD001246.

DOI: 10.1002/14651858.CD001246.pub2.

www.cochranelibrary.com

Thienopyridine derivatives versus aspirin for preventing stroke and other serious vascular events in high vascular risk patients (Review) 
TABLE OF CONTENTS

HEADER

ABSTRACT

PLAIN LANGUAGE SUMMARY

BACKGROUND

OBJECTIVES

METHODS

RESULTS

DISCUSSION

AUTHORS' CONCLUSIONS

ACKNOWLEDGEMENTS

REFERENCES

CHARACTERISTICS OF STUDIES

DATA AND ANALYSES

Analysis 1.1. Comparison 1 Thienopyridine versus aspirin in high vascular risk patients, Outcome 1 Stroke, MI or vascular death during follow up.

Analysis 1.2. Comparison 1 Thienopyridine versus aspirin in high vascular risk patients, Outcome 2 Stroke, MI or vascular death (thienopyridine subgroups).

Analysis 1.3. Comparison 1 Thienopyridine versus aspirin in high vascular risk patients, Outcome 3 Stroke (of all types) during follow up.

Analysis 1.4. Comparison 1 Thienopyridine versus aspirin in high vascular risk patients, Outcome 4 Ischaemic/unknown stroke during follow up.

Analysis 1.5. Comparison 1 Thienopyridine versus aspirin in high vascular risk patients, Outcome 5 Haemorrhagic stroke (symptomatic intracranial haemorrhage) during follow up.

Analysis 1.6. Comparison 1 Thienopyridine versus aspirin in high vascular risk patients, Outcome 6 Myocardial infarction (MI) during follow up.

Analysis 1.7. Comparison 1 Thienopyridine versus aspirin in high vascular risk patients, Outcome 7 Vascular death during follow up.

Analysis 1.8. Comparison 1 Thienopyridine versus aspirin in high vascular risk patients, Outcome 8 Death from any cause during follow up.

Analysis 1.9. Comparison 1 Thienopyridine versus aspirin in high vascular risk patients, Outcome 9 Extracranial haemorrhage during follow up.

Analysis 1.10. Comparison 1 Thienopyridine versus aspirin in high vascular risk patients, Outcome 10 Gastrointestinal haemorrhage during follow up.

Analysis 1.11. Comparison 1 Thienopyridine versus aspirin in high vascular risk patients, Outcome 11 Indigestion/nausea/ vomiting during follow up.

Analysis 1.12. Comparison 1 Thienopyridine versus aspirin in high vascular risk patients, Outcome 12 Neutropenia during follow up.

Analysis 1.13. Comparison 1 Thienopyridine versus aspirin in high vascular risk patients, Outcome 13 Any neutropenia (thienopyridine subgroups).

Analysis 1.14. Comparison 1 Thienopyridine versus aspirin in high vascular risk patients, Outcome 14 Thrombocytopenia during follow up.

Analysis 1.15. Comparison 1 Thienopyridine versus aspirin in high vascular risk patients, Outcome 15 Any thrombocytopenia (thienopyridine subgroups).

Analysis 1.16. Comparison 1 Thienopyridine versus aspirin in high vascular risk patients, Outcome 16 Skin rash during follow up.

Analysis 1.17. Comparison 1 Thienopyridine versus aspirin in high vascular risk patients, Outcome 17 Any skin rash (thienopyridine subgroups).

Analysis 1.18. Comparison 1 Thienopyridine versus aspirin in high vascular risk patients, Outcome 18 Diarrhoea during follow up.

Analysis 1.19. Comparison 1 Thienopyridine versus aspirin in high vascular risk patients, Outcome 19 Any diarrhoea (thienopyridine subgroups).

Analysis 2.1. Comparison 2 Thienopyridine versus aspirin in patients with TIA or ischaemic stroke, Outcome 1 Stroke, MI, or vascular death during follow up. 
Analysis 2.2. Comparison 2 Thienopyridine versus aspirin in patients with TIA or ischaemic stroke, Outcome 2 Ischaemic/ unknown stroke during follow up.

Analysis 2.3. Comparison 2 Thienopyridine versus aspirin in patients with TIA or ischaemic stroke, Outcome 3 Stroke (of all types) during follow up.

Analysis 2.4. Comparison 2 Thienopyridine versus aspirin in patients with TIA or ischaemic stroke, Outcome 4 Haemorrhagic stroke (symptomatic intracranial haemorrhage) during follow up.

Analysis 3.1. Comparison 3 Thienopyridine versus aspirin in high vascular risk patients - sensitivity analysis, Outcome 1 Serious vascular events (sensible worst case scenario).

APPENDICES

WHAT'S NEW

HISTORY

CONTRIBUTIONS OF AUTHORS

DECLARATIONS OF INTEREST

SOURCES OF SUPPORT

INDEX TERMS 
[Intervention Review]

\section{Thienopyridine derivatives versus aspirin for preventing stroke and other serious vascular events in high vascular risk patients}

Cathie LM Sudlow ${ }^{1}$, Gillian Mason², James B Maurice ${ }^{3}$, Catherine J Wedderburn³, Graeme J Hankey4

1Division of Clinical Neurosciences, University of Edinburgh, Edinburgh, UK. ${ }^{2}$ Maroondah Hospital, Melbourne, Australia. ${ }^{3}$ College of Medicine and Veterinary Medicine, University of Edinburgh, Edinburgh, UK. ${ }^{4}$ Department of Neurology, Royal Perth Hospital, Perth, Australia

Contact address: Cathie LM Sudlow, Division of Clinical Neurosciences, University of Edinburgh, Western General Hospital, Crewe Road, Edinburgh, EH4 2XU, UK. cathie.sudlow@ed.ac.uk.

Editorial group: Cochrane Stroke Group

Publication status and date: New search for studies and content updated (no change to conclusions), published in Issue 1, 2010.

Citation: Sudlow CLM, Mason G, Maurice JB, Wedderburn CJ, Hankey GJ. Thienopyridine derivatives versus aspirin for preventing stroke and other serious vascular events in high vascular risk patients. Cochrane Database of Systematic Reviews 2009, Issue 4. Art. No.: CD001246. DOI: 10.1002/14651858.CD001246.pub2.

Copyright (c) 2010 The Cochrane Collaboration. Published by John Wiley \& Sons, Ltd.

\section{A B S T R A C T}

\section{Background}

Aspirin is the most widely studied and prescribed antiplatelet agent for preventing serious vascular events, reducing the odds of such events among high vascular risk patients by about a quarter. Thienopyridine derivatives inhibit platelet activation by a different mechanism and so may be more effective.

\section{Objectives}

To determine the effectiveness and safety of thienopyridine derivatives (ticlopidine and clopidogrel) versus aspirin for preventing serious vascular events (stroke, myocardial infarction (MI) or vascular death) in patients at high risk, and specifically in patients with a previous TIA or ischaemic stroke.

\section{Search methods}

We searched the trials registers of the Stroke, Heart and Peripheral Vascular Diseases Cochrane Review Groups (last searched July 2008), the Cochrane Central Register of Controlled Trials (CENTRAL) (The Cochrane Library Issue 3, 2008), MEDLINE (1966 to August 2008 ) and EMBASE (1980 to August 2008). We also searched reference lists of relevant papers, and contacted other researchers and the pharmaceutical company Sanofi-BMS (December 2008).

\section{Selection criteria}

All unconfounded, double blind, randomised trials directly comparing a thienopyridine derivative with aspirin in high vascular risk patients.

\section{Data collection and analysis}

Two review authors independently extracted data and assessed trial quality. We sought additional data from the principal investigators of the largest trials.

\section{Main results}

We included 10 trials involving 26,865 high vascular risk patients. The trials were generally of high quality. Aspirin was compared with ticlopidine in nine trials (7633 patients) and with clopidogrel in one trial (19,185 patients). Compared with aspirin, allocation to a thienopyridine produced a modest, just statistically significant, reduction in the odds of a serious vascular event (11.6\% versus $12.5 \%$; odds ratio (OR) 0.92 , 95\% confidence interval (Cl) 0.85 to 0.99 ), corresponding to the avoidance of 10 ( $95 \% \mathrm{Cl} 0$ to 20 ) serious vascular

Thienopyridine derivatives versus aspirin for preventing stroke and other serious vascular events in high vascular risk patients (Review) 
events per 1000 patients treated for about two years. However, the wide confidence interval includes the possibility of negligible additional benefit. Compared with aspirin, thienopyridines significantly reduced gastrointestinal adverse effects. However, thienopyridines increased the odds of skin rash and diarrhoea, ticlopidine more than clopidogrel. Allocation to ticlopidine, but not clopidogrel, significantly increased the odds of neutropenia. In patients with TIA/ischaemic stroke, the results were similar to those for all patients combined.

\section{Authors' conclusions}

The thienopyridine derivatives are at least as effective as aspirin in preventing serious vascular events in patients at high risk, and possibly somewhat more so. However, the size of any additional benefit is uncertain and could be negligible. Clopidogrel has a more favourable adverse effects profile than ticlopidine and so is the thienopyridine of choice. It should be used as an alternative to aspirin in patients genuinely intolerant of or allergic to aspirin.

\section{PLAIN LANGUAGE SUMMARY}

\section{Thienopyridine derivatives versus aspirin for preventing stroke and other serious vascular events in high vascular risk patients}

Most strokes and heart attacks are caused by a blood clot blocking the blood supply to part of the brain (to cause stroke) or to the heart (to cause a heart attack). Aspirin prevents blood clots forming, and it can reduce the risk of a further heart attack or stroke in people who have had a stroke or heart attack or other symptoms of vascular disease. Clopidogrel and ticlopidine are two similar drugs called thienopyridines which prevent clots in a different way to aspirin. This review of 10 trials comparing either clopidogrel or ticlopidine with aspirin in about 27,000 people found that clopidogrel and ticlopidine were at least as effective as aspirin for the prevention of stroke and heart attacks, and might be slightly more effective. In terms of adverse effects, compared with aspirin, clopidogrel and ticlopidine caused less stomach upset and less bleeding from the gut, but more diarrhoea and skin rash. Ticlopidine produced more of these last two adverse effects than clopidogrel when compared with aspirin. Ticlopidine can also cause suppression of the bone marrow production of blood cells, which can be a serious complication. Clopidogrel is therefore the thienopyridine of choice since it is safer and better tolerated. However, since it is substantially more expensive than aspirin and not clearly more effective, it should generally only be used instead of aspirin in patients who are unable to take aspirin. 


\section{B A C K G R O U N D}

The burden of cardiovascular disease (mainly due to stroke and myocardial infarction (MI)) on patients, carers and communities is enormous. One strategy of reducing this burden is the effective prevention of serious vascular events (i.e. stroke, MI, or vascular death) among individuals who are at high risk as a result of previous clinical manifestations of atherosclerotic arterial disease (i.e. patients with a history of transient ischaemic attack (TIA) of the brain or eye, ischaemic stroke, MI or angina, or peripheral arterial disease (PAD)).

The most recently published systematic overview of the Antithrombotic Trialists' Collaboration (ATT) includes data from 287 randomised trials comparing antiplatelet therapy with control or one antiplatelet with another, in more than 200,000 individuals (ATT 2002). Many additional trials of aspirin at various doses and other antiplatelet drugs and also trials comparing the effects of adding aspirin to another antiplatelet drug with a different mechanism of action have been included since the previous published overview of the Antiplatelet Trialists Collaboration (APT). The additional data strengthens the findings from the APT that antiplatelet therapy for individuals with clinical manifestations of atherosclerotic arterial disease reduced the odds of a subsequent serious vascular event by about a quarter (APT 1994).

The proportional odds reductions were similar for patients with arterial disease of the brain, heart or peripheral circulation, but the absolute risk reductions varied according to the baseline risk of a subsequent vascular event. For example, among patients with prior TIA or ischaemic stroke, antiplatelet therapy reduced the three-year risk of a subsequent serious vascular event from $21 \%$ to $18 \%$ (a $22 \%$ relative odds reduction and $3 \%$ absolute risk reduction), indicating that treating 1000 such patients for about three years prevented or delayed about 30 major vascular events (ATT 2002).

In the most recent ATT overview, two-thirds of the data comparing an antiplatelet regimen with control came from trials comparing aspirin alone with no antiplatelet therapy. Overall, aspirin reduced the relative odds of a serious vascular event by about a quarter. Neither indirect nor direct comparisons of different aspirin regimens showed any evidence of differences in effectiveness throughout a range of doses from $75 \mathrm{mg}$ to $1500 \mathrm{mg}$ per day (ATT 2002). The number of participants in trials assessing doses of less than $75 \mathrm{mg}$ were relatively small and hence the results for benefits versus risks at this dose were not entirely conclusive (ATT 2002). Doses of 75 to $150 \mathrm{mg}$ daily have been much more widely assessed and since higher doses are significantly more gastrotoxic (Patrono 1989) the current evidence supports the use of aspirin 75 to $150 \mathrm{mg}$ daily for the prevention of vascular events in high risk individuals.

Indirect comparisons with aspirin of various different antiplatelet drugs in the most recent ATT overview showed no clear evidence of differences in the occurrence of vascular events, but the most promising drug in such comparisons was ticlopidine, which produced a $32 \%$ (95\% confidence interval (Cl) $21 \%$ to $42 \%$ ) odds of a serious vascular event compared to a $23 \%(95 \% \mathrm{Cl} 19 \%$ to $27 \%)$ odds reduction with aspirin alone. However, indirect comparisons are unreliable and direct comparisons between ticlopidine and aspirin among a total of 3791 high vascular risk patients in four trials showed no definite difference, although there was a non-significant trend toward a lower rate of serious vascular events in those treated with ticlopidine (odds reduction 12\%, 95\% Cl $-3 \%$ to $25 \%$ ) (ATT 2002).

Whilst these results may reflect a truly greater benefit of ticlopidine compared with aspirin, they may merely reflect the play of chance. Nevertheless, it is biologically plausible that ticlopidine is a more effective antiplatelet agent than aspirin because it inhibits a completely different pathway of platelet activation. Aspirin inhibits platelet activation by inhibiting platelet cyclooxygenase, and thromboxane production (Patrono 1994). By contrast, ticlopidine inhibits the binding of adenosine diphosphate (ADP) to its receptor on platelets, thereby inhibiting ADP-dependent activation of the glycoprotein IIb-IIla complex, the major receptor for fibrinogen on the platelet surface and the final common pathway of platelet activation (McTavish 1990).

The ATT overview also included a large randomised trial directly comparing another thienopyridine antiplatelet drug, clopidogrel, versus aspirin (CAPRIE). Clopidogrel is chemically related to ticlopidine and also inhibits platelet activation by selectively and irreversibly blocking the binding of ADP to its receptor on platelets. In platelet aggregation studies, clopidogrel $75 \mathrm{mg}$ once daily produced inhibition of ADP-induced platelet aggregation equivalent to that of ticlopidine, $250 \mathrm{mg}$ twice daily (Hebert 1993). It was licensed in the USA and Europe following the results of the large randomised, blinded trial of clopidogrel ( $75 \mathrm{mg}$ once daily) versus aspirin (325 mg once daily) in 19,185 patients at risk of ischaemic events (CAPRIE). After a mean follow up of 1.91 years, an intention-to-treat analysis showed that patients randomised to take clopidogrel had an annual risk of ischaemic stroke, MI, or non-haemorrhagic vascular death (the primary outcome event) of $5.3 \%$, compared with $5.8 \%$ for patients taking aspirin (relative risk reduction: $8.7 \%, 95 \% \mathrm{Cl} 0.3$ to $16.5 \% ; \mathrm{P}=0.04$; absolute risk reduction: $0.5 \%$ per year). There were no major differences in terms of safety. In particular, there was no excess neutropenia or thrombocytopenia among patients treated with clopidogrel. This is in contrast to ticlopidine, which is associated with an excess of neutropenia and thrombocytopenia (Moloney 1993), and is no longer widely used in Europe, USA, or Australasia.

Since thienopyridine drugs are chemically related, and have very similar modes of action on platelets, we have considered all the available randomised trials comparing any thienopyridine derivative with aspirin together in order to (1) minimise bias that may arise from considering the results of one trial rather than all relevant trials addressing a similar question, and (2) reduce the effects of random error in the assessment of the benefits and risks of treatment. In general, because the relative difference between the clinically relevant benefits of two active treatments is likely to be small (say about 10\%), large numbers of outcome events, and thus very large numbers of randomised patients (several tens of thousands), are required to assess any such difference reliably. In this updated version of our review we have been able to include several relevant randomised trials that have become available since the ATT overview was published.

\section{O B J E C T IVES}

Our objective was to determine the relative effectiveness and safety of thienopyridine derivatives (ticlopidine and clopidogrel), compared directly with aspirin (the current most commonly used first line antiplatelet drug), for the prevention of stroke and other serious vascular events in patients at high vascular risk (i.e. those 
with previous TIA, ischaemic stroke, MI, angina, or PAD), and specifically in patients with previous TIA and ischaemic stroke, amongst whom the risk of a subsequent stroke is particularly high.

\section{METHODS}

\section{Criteria for considering studies for this review}

\section{Types of studies}

We included all truly randomised trials in which a thienopyridine derivative (ticlopidine, clopidogrel or any other more recently developed thienopyridine) was compared directly with aspirin and in which patients were followed up prospectively and systematically for the occurrence of serious vascular events for at least one month.

\section{Types of participants}

Eligible patients were those at high risk of occlusive arterial disease due to previous clinical manifestations of atherosclerotic arterial disease of the cerebral, coronary or peripheral circulations.

\section{Types of interventions}

Orally administered thienopyridine antiplatelet drug compared with aspirin.

\section{Types of outcome measures}

The main outcome measure of effectiveness was the composite outcome of stroke, MI, or death from a vascular cause.

Secondary outcomes of effectiveness were the separate outcomes of stroke (ischaemic or haemorrhagic, non-fatal or fatal), MI (nonfatal or fatal), vascular death, and death from all causes.

Deaths were classified as due to ischaemic stroke, intracranial haemorrhage, MI, other vascular causes (e.g. sudden cardiac death, cardiac failure, ruptured aortic aneurysm, pulmonary embolism, extracranial haemorrhage), non-vascular causes, or of unknown cause (deaths that could not be assigned to any of the foregoing categories).

The main outcomes of safety were any intracranial haemorrhage, extracranial haemorrhage, gastrointestinal haemorrhage, neutropenia and thrombocytopenia.

Other outcomes of safety were skin rash, diarrhoea, and the composite outcome of indigestion, nausea and vomiting.

We used each trial's own definitions of the outcome events. If we extracted data on 'any' or 'severe' occurrences of safety outcomes, we used each trial's own definition of 'severe'.

\section{Search methods for identification of studies}

See the 'Specialised register' section in the Cochrane Stroke Group module.

We searched the trials registers of the following Cochrane Review Groups: Stroke Group, Heart Group and Peripheral Vascular Diseases Group (last searched July 2008), the Cochrane Central Register of Controlled Trials (CENTRAL) (The Cochrane Library Issue 3, 2008), MEDLINE (1966 to August 2008) (Appendix 1) and EMBASE (1980 to August 2008) (Appendix 2). We sought additional unpublished information and data from the principal investigators of the CAPRIE trial (CAPRIE), from the manufacturer of ticlopidine and clopidogrel, Sanofi-BMS (last contact December 2008), and from the principal investigator of AAASPS (AAASPS). For the previous version of this review in 1999, we searched the Antithrombotic Trialists' database which is now no longer available.

We obtained translations of reports in languages other than English from native speakers of the relevant language or from contact with the original authors, or both.

\section{Data collection and analysis}

Two authors (CLMS and GH or GM) independently reviewed potentially eligible studies, and extracted available details on the types of patients enrolled, the entry and exclusion criteria, the randomisation method (i.e. generation and concealment of the randomisation sequence), the number of patients originally allocated to the treatment group (thienopyridine) and the control group (aspirin), the method and duration of follow up, the number of patients in each group lost to follow up, information on compliance with the treatment allocated, the definitions of outcome events, the number of outcome events in each treatment group, and any method used for blinding patients, treating clinicians and outcome assessors to treatment allocation.

We resolved any disagreements among the authors by discussion and mutual consensus.

We analysed data on the basis of intention to treat, including every patient who was assigned to each treatment group, regardless of whether they actually complied with the allocated treatment, were subsequently deemed ineligible or otherwise excluded, or subsequently lost to follow up. In the main analyses we assumed that patients who were randomised and then either excluded or lost to follow up had no outcome event.

We calculated a weighted estimate of the odds ratio (OR) for each outcome using the Peto fixed-effect method.

We calculated absolute risk reductions (ARR) using the risk difference and expressed these as events prevented per 1000 patients treated.

We used the $\mathrm{Chi}^{2}$ and $\mathrm{I}^{2}$ statistics to assess heterogeneity between trials.

For the primary outcome we carried out subgroup analyses in which we assessed the effects of each thienopyridine drug versus aspirin separately. We performed similar subgroup analyses for the safety outcomes of neutropenia, thrombocytopenia, skin rash and diarrhoea, since we had identified differences between clopidogrel and ticlopidine with respect to these outcomes in the previous version of this review.

To assess for consistency of the main effects in participants presenting with a stroke or TIA, we repeated analyses for the primary outcome and for stroke outcomes for these participants only.

We performed a sensitivity analysis to test the robustness to losses to follow up of the result for the primary outcome of serious vascular events in all high risk patients. For each trial we assumed that amongst patients lost to follow up from the thienopyridine

Thienopyridine derivatives versus aspirin for preventing stroke and other serious vascular events in high vascular risk patients (Review) Copyright (c) 2010 The Cochrane Collaboration. Published by John Wiley \& Sons, Ltd. 
group, the proportion of vascular events experienced was the same as in the aspirin group, and that amongst patients lost to follow up from the aspirin group, the proportion of vascular events experienced was the same as in the thienopyridine group.

\section{RES U L T S}

\section{Description of studies}

We identified a total of 10 completed randomised trials that met our inclusion criteria (AAASPS; CAPRIE; De Lucia 2000; JapaneseB; Li 2000; Sadowski 1995; Schoop 1983; STAMI, TASS; Zhu 2001). All trials were conducted in the past 20 years, and included a total of 26,865 patients, most of whom participated in CAPRIE $(19,185)$ TASS (3069), AAASPS (1809) and STAMI (1470).

The patients were on average about 62 years of age, and $70 \%$ were men.

Aspirin was compared with clopidogrel in one trial of 19,185 patients with a qualifying diagnosis of recent (within one week to six months) ischaemic stroke (6431 patients), recent (within 35 days) MI (6302 patients) or PAD (6452 patients) (CAPRIE). Aspirin was compared with ticlopidine in the remaining nine studies in a total of 7,633 patients. These patients had recently diagnosed TIA or mild ischaemic stroke (5828 patients) (AAASPS; De Lucia 2000; Japanese-B; Li 2000; TASS; Zhu 2001), MI or angina (1790 patients) (Sadowski 1995; STAMI) or PAD (62 patients) (Schoop 1983). In one trial, three different doses of aspirin were each compared to ticlopidine (Zhu 2001). The most common dose of aspirin used in the 10 trials was $325 \mathrm{mg}$.

In CAPRIE, some of the patients who presented with a recent MI had also experienced a previous stroke, and likewise, some patients with a recent ischaemic stroke had also had a previous MI.

The duration of follow up varied between three and 40 months, with an average of about two years.

All trials recorded death, stroke, $\mathrm{MI}$, and vascular death as major outcome events with the exception of two (Li 2000; Zhu 2001). Seven trials $(26,255$ patients) contributed to the main primary outcome as no numerical data were available for one other trial (De Lucia 2000).

A summary of the details of each of the trials included is in the Characteristics of included studies table.

\section{Risk of bias in included studies}

The methodological quality of the CAPRIE, TASS and AAASPS studies was high. Treatment allocation was randomised in all studies but the methods of randomisation and allocation concealment were not stated in seven (De Lucia 2000; Japanese-B; Li 2000; Sadowski 1995; Schoop 1983; STAMI; Zhu 2001). In three of these neither patients nor investigators were blinded (Li 2000; Schoop 1983; Zhu 2001). There were no important imbalances in known prognostic factors at baseline that might invalidate the results.

Seven trials reported losses to follow up (AAASPS; CAPRIE; Japanese-B; Li 2000; STAMI; TASS; Zhu 2001). The proportion of patients lost to follow up was low, averaging $2 \%$ of the total number of patients. However, in AAASPS the proportion lost to follow up may have been as high as $14 \%$ as it was unclear how many patients in each arm were actually lost to follow up and how many withdrew but were still followed up to the end of the trial. In order to account for these losses we performed a sensitivity analysis. We were unable to include one trial that contributed to the primary outcome in the sensitivity analysis as it did not include any information on losses to follow up (Sadowski 1995).

In three trials (Li 2000; Japanese-B; Zhu 2001) including a total of 850 patients, losses to follow up were not included in the analyses presented in the trial reports making true intention-totreat analysis impossible. However, we included all patients lost to follow up in the analyses in the denominator for all but one trial for which the number in each treatment arm was unavailable (Zhu 2001).

\section{Effects of interventions}

Of the 26,865 patients randomised in the 10 trials, the qualifying event was a recent TIA or ischaemic stroke in 12,259 patients, recent MI in 8092 patients, and PAD in 6514 patients.

The results presented below are derived from data extracted from publications (AAASPS; CAPRIE; Japanese-B; Li 2000; Sadowski 1995; Schoop 1983; STAMI; TASS; Zhu 2001), supplemented by additional unpublished data provided by the principal investigators of the CAPRIE trial, and one internal report (Schoop 1983). No numerical data was available for one trial (De Lucia 2000). The results are illustrated in the figures.

The TASS study presented its results for outcomes of effectiveness in terms of first outcome events. For composite outcome events (e.g. stroke, Ml or vascular death) this strategy ensures that no patient is counted more than once. However, for specific single outcome events (e.g. stroke) this strategy can lead to undercounting (e.g. a patient with a non-fatal MI followed by a nonfatal stroke during the follow-up period will only be counted as having a non-fatal MI). Therefore, in TASS, the absolute number of strokes and MIs may have been undercounted. This strategy should not affect the estimates of the proportional effects of treatment because it applies to patients in both treatment groups, and without bias.

\section{All high vascular risk patients}

\section{Serious vascular events (stroke, MI, or vascular death)}

Data from seven trials including 26,255 patients ( $98 \%$ of the total) showed that allocation to a thienopyridine was associated with a modest, just significantly lower risk of the composite outcome stroke, MI or vascular death (thienopyridine 1519/13119 (11.6\%) versus aspirin $1641 / 13136(12.5 \%)$, OR $0.92,95 \% \mathrm{Cl} 0.85$ to 0.99$)$, corresponding to the avoidance of about 10 ( $95 \% \mathrm{Cl} 0$ to 20$)$ serious vascular events per 1000 patients treated with a thienopyridine rather than aspirin for an average of about two years (Analysis 1.1). There was moderate but not statistically significant heterogeneity between results for the seven trials $\left(I^{2}=38 \%\right.$; $\mathrm{Chi}^{2}(6 \mathrm{df})=9.7$; $P=0.1$ ). Results for the ticlopidine versus aspirin and clopidogrel versus aspirin trial subgroups were similar (Analysis 1.2).

\section{Stroke of all types}

Data were available from seven trials including $98 \%$ of the total number of patients in the 10 included trials. Allocation to a thienopyridine was associated with a modest but non- 
significant reduction in the combination of fatal and non-fatal stroke (758/13114 (5.8\%) versus $827 / 13130(6.3 \%))$ (OR 0.91, $95 \% \mathrm{Cl}$ 0.82 to 1.01$)$, corresponding to the avoidance of about $5(95 \% \mathrm{Cl} 0$ to 10) strokes per 1000 patients treated for about two years (Analysis 1.3).

\section{Ischaemic stroke or stroke of unknown pathological type}

Data were available from five trials including 22,778 patients ( $85 \%$ of the total) (CAPRIE; Li 2000; Schoop 1983; TASS; Zhu 2001). There was a significant reduction in the combination of fatal and nonfatal ischaemic or unknown stroke among patients allocated a thienopyridine $(622 / 11355(5.5 \%))$ compared with those allocated aspirin (704/11423 (6.2\%)) (OR $0.89,95 \% \mathrm{Cl} 0.79$ to 0.99 ) (Analysis 1.4).

\section{Haemorrhagic stroke (intracranial haemorrhage)}

Data were available from four trials including $84 \%$ of the total number of patients in the 10 included trials. There was a nonsignificant trend toward a lower rate of haemorrhagic stroke among patients allocated a thienopyridine than among those allocated aspirin in the doses used $(43 / 11324(0.38 \%)$ versus $48 / 11321$ (0.42\%); OR $0.89,95 \% \mathrm{Cl} 0.59$ to 1.35 ) (Analysis 1.5 ).

\section{Myocardial infarction}

Data were available from seven trials including $98 \%$ of the total number of patients. Allocation to a thienopyridine was associated with a non-significant reduction in $\mathrm{MI}(421 / 13114$ (3.2\%) versus $472 / 13130$ (3.6\%); OR 0.89, 95\% Cl 0.78 to 1.02 ) (Analysis 1.6).

\section{Vascular or unknown cause of death during follow up}

Data were available from seven trials ( $98 \%$ of the total number of patients). Overall, there were slightly fewer vascular deaths $(539 / 13119(4.1 \%))$ in the thienopyridine group than in the aspirin group (569/13136 (4.3\%)) but the reduction was not statistically significant (OR $0.95,95 \% \mathrm{Cl} 0.84$ to 1.07 ) (Analysis 1.7).

\section{Death from any cause}

Seven trials including 26,255 patients ( $98 \%$ of the total) reported death during follow up. The mortality among patients allocated a thienopyridine (793/13119 (6.04\%)) was not significantly different from that among patients allocated aspirin (824/13136 (6.27\%)) (OR: $0.96,95 \% \mathrm{Cl} 0.87$ to 1.06 ) (Analysis 1.8 ).

\section{Extracranial haemorrhage (including gastrointestinal haemorrhage)}

Data were available on any extracranial haemorrhage from three trials including 22,316 patients ( $83 \%$ of the total), and on severe extracranial haemorrhage from two trials including 19,505 patients ( $73 \%$ of the total). There was no significant difference in either severe extracranial haemorrhage (100/9753 (1.03\%) versus $102 / 9752$ (1.05\%); OR: $0.98,95 \% \mathrm{Cl} 0.74$ to 1.29 ) or any extracranial haemorrhage (986/11159 (8.84\%) versus 988/11157 (8.86\%); OR: $1.0,95 \% \mathrm{Cl} 0.91$ to 1.09 ) (Analysis 1.9).

\section{Gastrointestinal (GI) haemorrhage}

Two trials (CAPRIE; TASS) in 22,254 patients (83\% of the total) reported results for any $\mathrm{Gl}$ haemorrhage and both revealed a statistically significant reduction among patients allocated a thienopyridine (198/11128 (1.8\%)) compared with those allocated aspirin $(276 / 11126(2.5 \%)$ ) (OR $0.71,95 \% \mathrm{Cl} 0.59$ to 0.86 ). Many fewer patients experienced severe GI haemorrhage (reported in three trials: AAASPS, CAPRIE and Schoop 1983, in a total of 21,056 patients, $78 \%$ of the total), but the odds reduction was similar (Analysis 1.10). These odds reductions correspond to around seven (two severe) fewer gastrointestinal haemorrhages per 1000 patients treated for about two years with a thienopyridine instead of aspirin.

\section{Indigestion/nausea/vomiting}

Thienopyridines were also associated with a lower rate of indigestion, nausea and vomiting (1666/11893 (14\%)) than aspirin (1925/11893 (16\%)) (OR 0.84, 95\% Cl 0.78 to $0.90 ; 20$ fewer patients with upper gastrointestinal symptoms per 1000 treated for about two years with a thineopyridine instead of aspirin). Many fewer patients experienced severe indigestion, nausea or vomiting, but the odds reduction was similar (Analysis 1.11).

\section{Neutropenia}

Two trials (22,254 patients, $83 \%$ of the total) reported results for any neutropenia $(<1.2 \times 109 / \mathrm{L})$ and three trials $(24,063$ patients, $90 \%$ of the total) reported results for severe neutropenia ( $<1 \times 109 /$ L). Pooled results suggested an excess of neutropenia in patients allocated a thienopyridine (OR $1.61,95 \% \mathrm{Cl} 1.01$ to 2.55 for any neutropenia; OR $2.02,95 \% \mathrm{Cl} 1.27$ to 3.21 for severe neutropenia) (Analysis 1.12). However, since there was substantial and significant heterogeneity between the results of the trials included $\left(1^{2}=89 \%\right.$; $\mathrm{Chi}^{2}(1 \mathrm{df})=8.9 ; \mathrm{P}=0.003$ for any neutropenia; $\mathrm{I}^{2}=71 \% ; \mathrm{Chi}^{2}(2 \mathrm{df})=$ $6.9 ; \mathrm{P}=0.03$ for severe neutropenia), the pooled results are difficult to interpret. The heterogeneity may arise in part from different effects on neutropenia of clopidogrel and ticlopidine; considering these two thienopyridines separately, the results do not suggest an excess risk of any neutropenia for clopidogrel versus aspirin (10/9599 (0.1\%) versus $16 / 9586$ ( $0.17 \%)$, OR $0.63,95 \% \mathrm{Cl} 0.29$ to $1.36)$, but show an excess risk of any neutropenia for ticlopidine versus aspirin (35/1529 (2.3\%) versus $12 / 1540(0.8 \%)$, OR $2.72,95 \%$ $\mathrm{Cl} 1.53$ to 4.84 , excess of about 15 per 1000 treated for about two years with ticlopidine versus aspirin) (Analysis 1.13).

\section{Thrombocytopenia}

Three trials $(22,464$ patients, $84 \%$ of the total) reported results for severe thrombocytopenia and two (20,655 patients, $77 \%$ of the total) for any thrombocytopenia. The data for any thrombocytopenia $\left(<100 \times 10^{9} / \mathrm{L}\right)$ showed no significant excess among patients treated with a thienopyridine. There was a nonsignificant trend towards an excess of severe thrombocytopenia ( $<80 \times 109 / \mathrm{L})$ among patients treated with a thienopyridine (22/11235 (0.2\%) versus $13 / 11229$ (0.12\%), OR: $1.67,95 \% \mathrm{Cl} 0.86$ to 3.25 ). There was no detectable heterogeneity between the trials included or between subgroups of trials grouped according to the thienopyridine compared with aspirin (ticlopidine or clopidogrel) (Analysis 1.14; Analysis 1.15).

\section{Skin rash}

Five trials (25,595 patients, $95 \%$ of the total) reported results for skin rash. Compared with aspirin, allocation to a thienopyridine was associated with an excess of any skin rash, but there was substantial heterogeneity between the results for the different trials $\left(\mathrm{I}^{2}=80 \%\right.$; Chi2 (4 df) $\left.=19.6 ; \mathrm{P}=0.0006\right)$ (Analysis 1.16). Much of this heterogeneity appeared to arise from differences between ticlopidine and clopidogrel in their effects on skin rash.

Thienopyridine derivatives versus aspirin for preventing stroke and other serious vascular events in high vascular risk patients (Review) 6 Copyright $\odot 2010$ The Cochrane Collaboration. Published by John Wiley \& Sons, Ltd. 
Subgroup analyses found that, compared with aspirin, ticlopidine produced about a twofold excess in skin rash (213/3196 (6.7\%) versus $106 / 3214$ (3.3\%), OR $2.08,95 \% \mathrm{Cl} 1.66$ to 2.61 , excess of about 30 patients per 1000 treated for about two years with ticlipodine versus aspirin) while clopidogrel produced about a onethird excess (578/9599 (6.0\%) versus 442/9586 (4.6\%), OR 1.32 , $95 \% \mathrm{Cl} 17$ to 1.50 , excess of about 15 patients treated for about two years with clopidogrel versus aspirin) (Analysis 1.17). Only one trial reported results for occurrence of severe skin rash (CAPRIE), revealing a higher rate with clopidogrel than aspirin, but this outcome occurred much less frequently (Analysis 1.16).

\section{Diarrhoea}

Five trials $(25,595$ patients, $95 \%$ of the total) reported results for diarrhoea. Allocation to a thienopyridine was associated with an excess of diarrhoea, but there was substantial heterogeneity between the results for the different trials (Analysis 1.18). This heterogeneity appeared to be accounted for by differences between ticlopidine and clopidogrel in their effects on diarrhoea. Subgroup analyses found that, compared with aspirin, ticlopidine produced about a twofold excess of diarrhoea (332/3196 (10.4\%) versus $160 / 3214$ (5\%); OR $2.3,95 \% \mathrm{Cl} 1.89$ to 2.77 , excess of about 50 patients per 1000 treated for about two years with ticlopidine versus aspirin), while clopidogrel produced about a one-third excess (428/9599 (4.5\%) versus 322/9586 (3.4\%); OR 1.34, 95\% Cl 1.16 to 1.55 , excess of about 10 patients per 1000 treated for about two years with clopidogrel versus aspirin) (Analysis 1.19). Data from the CAPRIE trial also revealed a trend towards a higher rate of severe diarrhoea with clopidogrel, compared with aspirin, but this outcome occurred much less frequently (Analysis 1.18).

\section{TIA or ischaemic stroke patients}

\section{Serious vascular events (stroke, MI, or vascular death)}

Data for the composite outcome event of stroke, MI or vascular death during follow up for $\mathrm{TIA} /$ ischaemic stroke patients were available from four trials (AAASPS; CAPRIE; Japanese-B; TASS). There was a modest but non-significant reduction in the odds of stroke, MI or vascular death among patients allocated a thienopyridine $(959 / 5834(16.4 \%))$ compared with those allocated aspirin (1009/5815 (17.4\%)) (OR: $0.94,95 \% \mathrm{Cl} 0.85$ to 1.03 ), corresponding to the avoidance of $10(95 \% \mathrm{Cl} 0$ to 20$)$ serious vascular events per 1000 patients treated for about two years (Analysis 2.1). This was similar to the overall result for this outcome for all high vascular risk patients (Analysis 1.1).

\section{Stroke of all types}

Data on stroke of all types during follow up for TIA/ischaemic stroke patients were available from five trials (AAASPS; CAPRIE; JapaneseB, Li 2000; TASS). The was a borderline statistically significant reduction in the odds of any stroke in the group of patients allocated a thienopyridine compared with those allocated aspirin: $632 / 5999(10.5 \%)$ patients in the thienopyridine group had a stroke compared with 696/5979 (11.6\%) in the aspirin group (OR: 0.89, $95 \% \mathrm{Cl} 0.8$ to 1$) ; 10$ (95\% Cl 0 to 20 ) strokes avoided per 1000 patients treated for two years (Analysis 2.3). The odds reduction is very similar to the result for this outcome for all high vascular risk patients (Analysis 1.3) but the higher overall risk of stroke in this subgroup of patients means that the absolute reduction in stroke is about twice as large, albeit estimated with substantial uncertainty with a wide confidence interval.

\section{Different pathological types of stroke}

There was a significant reduction in odds of ischaemic or unknown stroke among patients allocated a thienopyridine (490/4927 (9.9\%)) compared with those allocated aspirin (564/4902 (11.5\%)) (OR $0.85,95 \% \mathrm{Cl} 0.75$ to 0.97 ) (Analysis 2.2), but no clear difference between the rate of haemorrhagic stroke among patients allocated a thienopyridine $(34 / 7927(0.7 \%))$ and those allocated aspirin (35/4902 (0.7\%)) (OR 0.96, 95\% Cl 0.6 to 1.55$)$ (Analysis 2.4).

\section{Sensitivity analysis}

This analysis to assess robustness of overall results for the primary outcome to the potential bias caused by losses to follow up produced no material difference in the result (thienopyridine $1557 / 13119$ (11.9\%) versus aspirin 1673/13136 (12.7\%); OR: 0.92, $95 \% \mathrm{Cl} 0.86$ to 0.99 ) (Analysis 3.1).

\section{DISCUSSION}

This review summarises the available data from the 10 published randomised trials of a thienopyridine versus aspirin in patients at high risk of vascular events. Although data were incomplete for some of the outcome events, they were available for all outcomes of interest from the largest trial, contributing $71 \%$ of the patients randomised (CAPRIE), and for almost all of these outcomes for the second largest trial, contributing $11 \%$ of the patients randomised (TASS). Data were available for most outcomes of interest from the third and fourth largest trials contributing $12 \%$ of the patients randomized (AAASPS; STAMI). However, information on the type of stroke was unavailable for both these trials and since the STAMI trial was undertaken in participants with previous MI it did not contribute to analyses in the subset of patients with recent TIA or ischaemic stroke. The remaining trials were small and contributed in total only $6 \%$ of the patients randomised so most of the data reflect the results of the four largest studies (AAASPS; CAPRIE; STAMI; TASS).

Pooling the data from trials of clopidogrel and ticlopidine (the thienopyridines) versus aspirin increases the sample size and therefore the accuracy of the estimates. Similarly, combining the vascular outcome events into a composite outcome of stroke, MI or vascular death also increases the statistical power and it is this analysis which provides the most reliable (i.e. statistically robust) estimate of the effect of thienopyridines in high risk patients. This analysis reveals that the thienopyridines are just statistically significantly more effective than aspirin in preventing serious vascular events among high vascular risk patients, but the magnitude of the additional benefit is uncertain and could be negligible. The proportional odds (and risk) reduction was about $8 \%$, but may be as low as $1 \%$ or as high as $15 \%$ (the $95 \%$ confidence limits). If the average absolute annual risk of a serious vascular event with aspirin therapy is about $6 \%$ per year (CAPRIE), our best estimate would be that substituting aspirin with a thienopyridine may reduce this rate to about $5.5 \%$ ( $92 \%$ of $6 \%$ ), but could reduce it to anywhere between $5.1 \%(85 \%$ of $6 \%$ ) and $5.9 \%$ (99\% of $6 \%)$. This corresponds to an absolute risk reduction (ARR) of about $0.5 \%$, ranging between $0.1 \%$ and $0.9 \%$, and means that treating 1000 patients with thienopyridines may prevent between one and nine extra events each year compared with aspirin. The number of high vascular risk patients who would need to be treated with a thienopyridine to prevent one event per year, compared with aspirin, may therefore vary from 100 to 900 . 
In high vascular risk patients, the proportional effect of the thienopyridines, compared with aspirin, on each of the separate outcomes of stroke, $\mathrm{MI}$ and vascular death was similar to the effect on the primary outcome of serious vascular events (i.e. about $10 \%$ odds reduction). The reduction in stroke seems to be mainly due to a reduction in ischaemic stroke, since the thienopyridines were associated with a $11 \%$ reduction in the odds of ischaemic stroke and had no clear effect on haemorrhagic stroke compared with aspirin.

Caution should be exercised in the interpretation of subgroup analyses (e.g. in TIA/ischaemic stroke patients), particularly when the overall magnitude of the treatment effect (in all high vascular risk patients) is substantially uncertain. However, among patients with previous TIA/ischaemic stroke, the proportional reduction in the odds of the primary outcome of serious vascular events (and of each of the separate outcomes of stroke, MI and vascular death) associated with the thienopyridines was similar to that in all high risk patients.

Most of the trials included in this review included mainly white patients, although not all gave specific details of the ethnicity or ethnicities of the participants. One trial specifically included Black African-Americans only (AAASPS). Interestingly, in this trial there was a non-significant trend towards aspirin being more effective than ticlopidine for the primary outcome of vascular events as well as for its separate components. However, while it is possible that black and white patients respond differently to different antiplatelet drugs, perhaps because of their different distributions of ischaemic stroke subtypes, it is important to note that there was no statistically significant heterogeneity between the seven trials contributing data to the primary outcome, so that any apparent differences between trials (and between ethnic groups) may well have arisen due to chance alone.

In terms of adverse effects, the results of this review show that aspirin is associated with a greater risk of gastrointestinal haemorrhage and upper gastrointestinal adverse effects. It is worth bearing in mind that the most common dose of aspirin used in the trials included in this review was $325 \mathrm{mg}$ daily. The lower doses of 75 to $150 \mathrm{mg}$ daily that are generally in widespread use for prevention of vascular events in high risk patients nowadays may compare more favourably with clopidogrel with respect to gastrointestinal adverse effects. On the other hand, the thienopyridines are associated with a greater risk of skin rash and diarrhoea (ticlopidine more so than clopidogrel) and ticlopidine is associated with an excess of neutropenia while clopidogrel appears not to be. Observational studies have found ticlopidine to be associated with a significant excess both of thrombocytopenia and thrombotic thrombocytopenic purpura (Bennett 1999; Moloney 1993; Steinhubl 1999; Torok 1995), and have shown clopidogrel to be associated with a very small (but not negligible) risk of thrombotic thrombocytopenic purpura (Zakarija 2004). The data from these observational studies, as well as from our review, and from short-term direct randomised comparisons between clopidogrel and ticlopidine, both in the presence of aspirin, among patients undergoing coronary stenting procedures (Bertrand 2000; Müller 2000), show that clopidogrel and ticlopidine have similar efficacy but clopidogrel has a more favourable safety and tolerability profile,

For every 1000 patients treated for about two years with either clopidogrel or aspirin, aspirin causes around seven more patients to have a gastrointestinal haemorrhage (two severe) and around 20 more to have upper gastrointestinal symptoms, while clopidogrel causes around 15 more patients to have a skin rash and around 10 more to have diarrhoea. It is difficult to compare these different outcomes directly, but these data would suggest that the two drugs have approximately similar safety and tolerability.

Clopidogrel is substantially more expensive than aspirin ( $£ 460$ versus $£ 2$ per patient per year) (BNF 2008). Since it is not clearly more effective than aspirin, it should generally only be used as monotherapy in patients who are genuinely intolerant of or allergic to aspirin. Furthermore, in patients developing upper gastrointestinal adverse effects with aspirin, the addition of a proton pump inhibitor to aspirin is both safer and cheaper than switching to clopidogrel (Chan 2005). Proton pump inibitors reduce the risk of upper gastrointestinal peptic ulcer bleeding for patients taking either aspirin or clopidogrel (Lanas 2007), but there are concerns about the effectiveness of clopidogrel given together with a proton pump inhibitor because these drugs are thought to inhibit the antiplatelet effects of clopidogrel, and a large observational study has suggested that this may adversely affect clinical outcomes (Ho 2009).

The combination of clopidogrel with aspirin has now been demonstrated in randomised trials to be of net benefit compared with aspirin alone in the early months after an acute coronary syndrome or percutaneous coronary intervention (Sabatine 2005). But, in patients with a prior ischaemic stroke or TIA the combination increased the risk of haemorrhage without increasing net benefit compared with cloidogrel alone (MATCH 2004), and in high vascular risk patients with a prior ischaemic stroke or TIA, peripheral arterial disease, stable coronary artery disease or vascular risk factors the combination was not superior to aspirin alone (CHARISMA 2006). However, there were promising results for the combination from the subgroup of patients randomised within a week of onset of ischaemic stroke or transient ischaemic attack in the MATCH trial of aspirin plus clopidogrel versus clopidogrel alone (MATCH 2004), from a small randomised pilot trial of clopidogrel plus aspirin versus aspirin alone started within 24 hours of minor ischaemic stroke or transient ischaemic attack (FASTER), and from a randomised trial showing that adding clopidogrel to aspirin reduced transcranial Doppler ultrasound signals (thought to represent asymptomatic emboli) in patients with severe carotid stenosis (CARESS). Together these suggest that the combination may be beneficial very early after ischaemic stroke or TIA when the recurrence risk is particularly high.

Newer thienopyridine derivatives are now becoming available that may improve on the benefits of clopidogrel by producing a more consistent antiplatelet effect. Recent randomised trials have shown superiority of the combination of the new thienopyridine drug, prasugrel, plus aspirin compared with clopidogrel plus aspirin in patients with acute coronary syndromes, although at the expense of a higher haemorrage risk (TRITON-TIMI 38 2007). However, there are no direct randomised comparisons of any thienopyridine other than ticlopidine or clopidogrel with aspirin, and no current evidence base to support the use of prasugrel as antiplatelet monotherapy.

Current guidelines for prevention of further vascular events after ischaemic stroke or TIA suggest that the combination of aspirin with modifed release dipyridamole $200 \mathrm{mg}$ twice daily is the antiplatelet regimen of choice, based on the results of

Thienopyridine derivatives versus aspirin for preventing stroke and other serious vascular events in high vascular risk patients (Review) 8 Copyright $\odot 2010$ The Cochrane Collaboration. Published by John Wiley \& Sons, Ltd. 
two randomised trials comparing these two regimens in a total of about 6000 patients (ESPRIT; ESPS-2; NICE Guidelines; RCP Guidelines; SIGN Guidelines). However, a subsequent large trial in about 20,000 patients with a prior ischaemic stroke or TIA compared this combination with clopidogrel alone and found no difference in effects on vascular events (PRoFESS). When the available data from randomised trials of all three relevant comparisons (aspirin versus clopidogrel, aspirin versus aspirin plus modified release dipyridamole, and clopidogrel versus aspoirin plus modified release dipyridamole) were considered together in a network meta-analysis (PRoFESS Editorial), there were no overall significant differences, suggesting that there is still no antiplatelet regimen that is clearly superior to aspirin alone in long-term prevention in high vascular risk patients.

Finally, there remains the question of what to do about antiplatelet treatment when high vascular risk patients have further events while taking aspirin alone. This will to some extent be determined by the ASCET study, in which 1000 patients with documented coronary heart disease will be randomised to either continued treatment with aspirin $160 \mathrm{mg}$ daily or change to clopidogrel $75 \mathrm{mg}$ daily and followed for two years after initial determination of their platelet reactivity while on aspirin treatment (ASCET). However, further large trials addressing this question will be needed to generate reliable answers.

A further randomised trial, in which around 1000 patients with heart failure (mainly due to ischaemic heart disease) were randomised between aspirin and clopidogrel and followed for about two years, was published after the searches for the current version of this review had been completed (WATCH). It found no significant differences in the effects of the two antiplatelet drugs on the trial's stated primary outcome of all-cause mortality, non-fatal MI or nonfatal stroke (hazard ratio clopidogrel versus aspirin $1.08,95 \% \mathrm{Cl}$ 0.83 to 1.40 ), on any of the separate components of this primary outcome, or on intracranial or extracranial haemorrhages. From these results, it seems very unlikely that the formal inclusion of this trial in our systematic review would materially alter the results or conclusions.

\section{AUTHORS' CONCLUSIONS}

\section{Implications for practice}

The role of thienopyridines in clinical practice should be determined by the proportional reduction in risk of serious vascular events compared with alternative antiplatelet drugs, the absolute benefit they confer, their cost, and safety. Thienopyridines are at least as effective as aspirin and possibly somewhat more so. Ticlopidine and clopidogrel appear to be very similar in terms of efficacy and safety, except that ticlopidine is associated with more skin rash and diarrhoea as well as a risk of bone marrow suppression and thrombotic throbocytopenic pupura, making clopidogrel the thienopyridine of choice on safety and tolerability grounds. However, since clopidogrel is substantially more expensive than aspirin and the magnitude of any additional benefit ove aspirin is uncertain, it should generally only be used as monotherapy in patients who are genuinely intolerant of or allergic to aspirin.

\section{Implications for research}

Future large trials are needed to address two important, unresolved issues.

1. What clinicians should do about antiplatelet treatment when high vascular risk patients have further vascular events while taking aspirin alone. It remains unclear whether increasing the daily dose of aspirin, substituting aspirin with an alternative antiplatelet drug (eg. a theinopyridine such as clopidogrel) or adding another antiplatelet drug to aspirin are of net benefit in this situation.

2. Whether combining a thienopyridine derivative, such as clopidogrel, with aspirin is safe and more effective than either alone in the early very high risk period after acute ischaemic stroke or TIA when the recurrence risk is particularly high and the benefits may outweigh the risks. Despite this being a potentially promising strategy, at present there is no clear evidence to support the use of the combination in such patients.

\section{ACKNOWLEDGEMENTS}

We are very grateful to Hazel Fraser, Cochrane Stroke Group Managing Editor, for her help in preparing this review, to the referees, Professors Charles Warlow and Peter Sandercock (Cochrane Stroke Group Editors) and Dr Daniel Bereczki, for their helpful comments on previous versions of the review, and to Professors Mike Gent and Robin Roberts for providing additional unpublished data from the CAPRIE trial, and for their helpful comments on previous versions of the review. 


\section{R E F E R E N C E S}

\section{References to studies included in this review \\ AAASPS \{published data only\}}

Gorelick PB, Richardson D, Kelly M, Ruland S, Hung E, Harris Y, et al. Aspirin and ticlopidine for prevention of recurrent stroke in black patients. A randomised trial. JAMA 2003;289(22):2947-57.

\section{CAPRIE \{published and unpublished data\}}

CAPRIE Steering Committee. A randomised, blinded, trial of clopidogrel versus aspirin in patients at risk of ischaemic events (CAPRIE). Lancet 1996;348:1329-39.

\section{De Lucia 2000 \{published data only\}}

De Lucia D, Pezzella S, Maisto G, Del Giudice V, Lauretano M, Quartucci R, et al. Ticlopidine for patients on short-term incidence of ischemic stroke with high glycocalicin plasma levels. Journal of Neural Transmission 2000;107(5):42.

\section{Japanese-B \{published data only\}}

Murakami G, Toyokura Y, Omae T. Effects of aspirin and ticlopidine on transient ischaemic attack. Sindan To Chiryo 1986;74:2255-74.

Murakami M, Toyokura Y, Omae T, Gotoh F, Tazaki Y, Ohtomo E, et al. Effects of ticlopidine and aspirin on TIA - a twelve month, double blind comparative study. Igaku no Ayumi 1983;127(9):950-71.

Tohgi H. L'etude japonaise de la ticlopidine dans les accidents ischemiques transitoires. Maladies Cerebrovasculaires 1990;April:19-22.

Tohgi $\mathrm{H}$. The Japanese ticlopidine study in transient ischaemic attacks. Sang Thrombose Vaisseaux 1990;2(4):19-22.

Tohgi $\mathrm{H}$. The effect of ticlopidine on TIA compared with aspirin: a double-blind, twelve-month follow-up study. In: JL Gordon editor(s). Ticlopidine: Quo Vadis?. Vol. 15, Basel: Birkhauser Verlag, 1984:279-82.

* Tohgi H, Murakami M. The effect of ticlopidine on TIA compared with aspirin - a double-blind, twelve-month and open 24-month follow-up study. Japanese Journal of Medicine 1987;26(1):117-9.

\section{Li 2000 \{published data only\}}

* Li Y, Li D, Wang L. A prospective randomized control study on ticlopidine with aspirin for the prevention of ischaemic cerebral stroke. Journal of Clinical Neurology 2000;13(3):146-8.

Li Y-Z, Wang L, Yu P-X. A randomized trial comparing ticlopidine with aspirin for the prevention of ischaemic cerebral stroke. Acta Pharmacologica Sinica 1999;20(5):476.

\section{Sadowski 1995 \{published data only\}}

Sadowski Z, Kuczak D, Dyduszynski A, Giep L, Kalicinski A, Kraska T, et al. Comparison of ticlopidine and aspirin in unstable angina. European Heart Journal 1995;16 Suppl:259.
Schoop 1983 \{unpublished data only\}

Schoop W. Open randomised study comparing ticlopidine with acetylsalicylic acid in the prevention of contralateral thrombosis in patients initially presenting with unilateral thrombosis. Guildford: Sanofi Winthrop (Sanofi internal report 001.6.174) 1983.

STAMI \{published data only\}

Scrutinio D, Cimminiello C, Marubini E, Pitzalis MV, Di Biase M, Rizzon P. Ticlopidine versus aspirin after myocardial infarction (STAMI) trial. Journal of the American College of Cardiology 2001;37(5):1259-65.

\section{TASS \{published data only\}}

Hass WK, Easton JD, Adams HP, Pryse-Phillips W, Molony BA, Anderson S, et al. A randomised trial comparing ticlopidine hydrochloride with aspirin for the prevention of stroke in highrisk patients. New England Journal of Medicine 1989;321:501-7.

\section{Zhu 2001 \{published data only\}}

Zhu L-S, Ding J-F, Bian J. Analyses of controlled trial of prevention against ischaemic stroke with different agents and dosage for patients recovering from cerebral infarction. Modern Rehabilitation 2001;5(1):55-6.

\section{References to studies excluded from this review}

Abe 1981 \{published data only\}

Abe T, Kuramoto A, Yasunaga K. Clinical evaluation of ticlopidine in the inhibition of platelet function: A multiclinic double-blind study in comparison with aspirin. Thrombosis \& Haemostasis 1981;46(1):1300.

\section{Akyuz 1999 \{published data only\}}

Akyuz A, Bolayir E, Dener S, Topalkara K, Topaktas S. The effect of aspirin, ticlopidine and their low-dose combination on platelet aggregability in acute ischemic stroke: a short duration follow-up study. European Journal of Neurology 1999;6:57-61.

\section{Apollonio 1989 \{published data only\}}

Apollonio A, Castignani P, Magrini L, Angeletti R. Ticlopidinepentoxifylline combination in the treatment of atherosclerosis and the prevention of cerebrovascular accidents. Journal of International Medical Research 1989;17:28-35.

\section{Aramendi 1998 \{published data only\}}

Aramendi JL, Agredo J, Llorente A, Larrarte C, Pijoan J. Prevention of thromboembolism with ticlopidine shortly after valve repair or replacement with a bioprosthesis. Journal of Heart Valve Disease 1998;7:610-4.

\section{Bergamasco 1997 \{published data only\}}

Bergamasco B, Benna P, Carolei A, Rasura M, Rudelli G, Fieschi C, et al. A randomised trial comparing ticlopidine hydrochloride with indobufen for the prevention of stroke in high-risk patients (TISS study). Functional Neurology 1997;12:33-43. 


\section{Cooke 2006 \{published data only\}}

Cooke GE, Liu-Stratton Y, Ferketich AK, Moeschberger ML, Frid DJ, Magorien RD, et al. Effect of platelet antigen polymorphism on platelet inhibition by aspirin, clopidogrel, or their combination. Journal of the American College of Cardiology 2006;47:541-6.

\section{Dorr 2004 \{published data only\}}

Dorr G, Schmidt G, Grafe M, Regitz-Zagrosek V, Fleck E. Effects of combined therapy with clopidogrel and acetylsalicylic acid on platelet glycoprotein expression and aggregation. Journal of Cardiovascular Pharmacology 2002;39(4):523-32.

\section{Droste 1996 \{published data only\}}

* Droste DW, Siemans H-J, Sonne M, Kaps M, Wagner T. Hemostaseologic and hematologic parameters with aspirin and ticlopidine treatment in patients with cerebrovascular disease: a cross-over study. Journal of Cardiovascular Pharmacology 1996;28:591-4

Droste DW, Sonne M, Siemans H-J, Kaps M. Asymptomatic circulating cerebral emboli and cerebral blood flow velocity under aspirin and ticlopidine in patients with cerebrovascular disease. Neurological Research 1996;18:449-53.

Siemens A, Droste DW, Brueckner S, Sonne M, Koemp D, Wagner T. Differences in platelet aggregation in patients with cerebrovascular disease under ASA or ticlopidine. Thrombosis \& Haemostasis 1995;73(6):954.

\section{Eder 2007 \{published data only\}}

Eder C, Funke U, Schulze M, Lutze G, Zimmermann M, Prasse T, et al. Modified platelet aggregation test in patients on ASA and/ or clopidogrel. Hamostaseologie 2007;27:163-76.

\section{Fork 2000 \{published data only\}}

Fork FT, Lafolie P, Toth E, Lindgarde F. Gastroduodenal tolerance of $75 \mathrm{mg}$ clopidogrel versus $325 \mathrm{mg}$ aspirin in healthy volunteers. A gastroscopic study. Scandinavian Journal of Gastroenterology 2000;35(5):464-69.

\section{Jagroop 2004 \{published data only\}}

Jagroop IA, Matsagas MI, Geroulakos G, Mikhailidis DP. The effect of clopidogrel, aspirin and both antiplatelet drugs on platelet function in patients with peripheral arterial disease. Platelets 2004;15(2):117-25.

\section{Kindsvater 2003 \{published data only\}}

Kindsvater S, Leclerc K, Ward J. Effects of coadministration of aspirin or clopidogrel on exercise testing in patients with heart failure receiving angiotensin-converting enzyme inhibitors. American Journal of Cardiology 2003;91:1350-2.

\section{KTS 1999 \{published data only\}}

Chen WH, Lan MY, Peng MC, Wu SS, Ngai WK, Chang YY, et al. The Kaohsiung Medical College Hospital Ticlopidine Study (KTS): a five-year prospective study to follow the outcome and complication of ticlopidine hydrochloride in Taiwanese. Acta Neurologica Taiwanica 1999;8(2):126.

\section{Lim 2004 \{published data only\}}

Lim E, Cornelissen J, Routledge T, Kirtland S, Charman SC, Bellm S, et al. Clopidogrel did not inhibit platelet function early after coronary bypass surgery: a prospective randomized trial. Journal of Thoracic \& Cardiovascular Surgery 2004;128(3):432-35.

\section{Nomura 1996 \{published data only\}}

Nomura H, Morita C, Kuwano S, Eto H, Goto H, Kuwahara H. Efficacy of combination antiplatelet therapy and nicardipine for chronic cerebral infarction. Clinical Therapeutics 1996;18(3):483-9.

\section{Ozalp 1997 \{published data only\}}

* Ozalp K, Erdogan N, Tunali F, Misirli H, Erenoglu NY. Effect of ticlopidine and aspirin on plasma fibrinogen level. Cerebrovascular Diseases 1997;7 Suppl 4:53.

Ozalp K, Erdogan N, Tunali F, Misirli H, Erenoglu NY. Effect of ticlopidine and aspirin on plasma fibrinogen level. European Journal of Neurology 1997;4 Suppl 1:S119-20.

Rebrov 2001 \{published data only\}

Rebrov AP, Voskoboi IV. Comparative efficacy of tiklid and aspirin in patients with unstable angina. Terapevticheskii Arkhiv 2001;73(12):25-9.

\section{Rey 1996 \{published data only\}}

Rey A, Aguilar M, Bonaventura I, Martinez I, Quintana S. Antiaggregant treatment for cerebral ischemia: ticlopidine versus aspirin. Revista de Neurologia 1996;24(126):214-8.

\section{Rupprecht 1998 \{published data only\}}

Rupprecht HJ, Darius H, Borkowski U, Voigtländer T, Nowak B, Genth S, et al. Comparison of antiplatelet effects of aspirin, ticlopidine, or their combination after stent implantation. Circulation 1998;97:1046-52.

\section{Singh 1999 \{published data only\}}

Singh P, Kar AM, Nag D, Misra A, Shukla R, Agarwal A, et al. Effect of aspirin and ticlopidine, alone or combined, on platelet aggregation in acute ischaemic stroke. Journal of Internal Medicine of India 1999;2:300-4.

\section{Tokyo 1993 \{unpublished data only\}}

Uchiyama S. Safety and efficacy of ticlopidine alone or with aspirin in patients with cerebral infarction or TIA. Unpublished 1993.

\section{Vyshlov 2000 \{published data only\}}

Vyshlov EV, Panfilova EV, Markov VA. Aspirin vs ticlid and their combination in patients with acute myocardial infarction. Klinicheskaia Meditsina 2000;78:37-9.

\section{Woodward 2004 \{published data only\}}

Woodward M, Lowe GDO, Francis LMA, Rumley A, Cobbe SM, Bain $\mathrm{R}$, et al. Randomized comparison of the effects of aspirin and clopidogrel on thrombotic risk factors and C-reactive protein following myocardial infarction: the CADET trial. Journal of Thrombosis \& Haemostasis 2004;2(11):1934-40. 
Zucca 1992 \{published data only\}

Zucca R, Farina M, Basellini A, Bonalumi FA, Dellavedova M. Evaluation of ASA and ticlopidine treatment to prevent carotid restenosis after carotid TEA. Preliminary report. Proceedings of the 16th World Congress of the International Union of Angiology. 1992:338.

\section{References to studies awaiting assessment}

Bokarev 1998 \{published data only\}

Bokarev IN, Aksenova MB, Khlevchuk TV, Dovgolis SA. Effectiveness of unstable angina pectoris treatment by aggregation inhibitors ticlid and aspirin. Klinicheskaia Meditsina 1998;76:49-52.

\section{WATCH \{published data only\}}

Massie BM, Collins JF, Ammon SE, Armstrong PW, Cleland JG, Ezekowitz M, et al. Randomized trial of warfarin, aspirin, and clopidogrel in patients with chronic heart failure: the Warfarin and Antiplatelet Therapy in Chronic Heart Failure (WATCH) trial. Circulation 2009;119:1559-61.

\section{References to ongoing studies}

\section{ASCET \{published data only\}}

Pettersen AA, Seljeflot I, Abdelnoor M, Arnesen H. Unstable angina, stroke, myocardial infarction and death in aspirin nonresponders. A prospective, randomized trial. The ASCET (ASpirin non-responsiveness and Clopidogrel Endpoint Trial) design. Scandinavian Cardiovascular Journal 2004;38:353-6.

\section{Additional references}

\section{APT 1994}

Antiplatelet Trialists' Collaboration. Collaborative overview of randomised trials of antiplatelet therapy. I. Prevention of death, myocardial infarction, and stroke by prolonged antiplatelet therapy in various categories of patients. BMJ 1994;308:81-106.

\section{ATT 2002}

Antithrombotic Trialists' Collaboration. Collaborative metaanalysis of randomised trials of antiplatelet therapy for prevention of death, myocardial infarction, and stroke in high risk patients. BMJ 2002;324:71-86.

\section{Bennett 1999}

Bennett CL, Davidson CJ, Raisch DW. Thrombotic thrombocytopenic purpura associated with ticlopidine in the setting of coronary artery stents and stroke prevention. Archives of Internal Medicine 1999;159:2524-8.

\section{Bertrand 2000}

Bertrand ME, Rupprecht H-J, Urban P, Gershlick AH, for the CLASSICS Investigators. Double-blind study of the safety of clopidogrel with and without a loading dose in combination with aspirin compared with ticlopidine in combination with aspirin after coronary stenting. Circulation 2000;102:624-9.

\section{BNF 2008}

British National Formulary. http://www.bnf.org/bnf/ September 2008.

\section{CARESS}

Markus HS, Droste DW, Kaps M, Larrue V, Lees KR, Siebler M, et al. Dual antiplatelet therapy with clopidogrel and aspirin in symptomatic carotid stenosis evaluated using doppler embolic signal detection: the Clopidogrel and Aspirin for Reduction of Emboli in Symptomatic Carotid Stenosis (CARESS) trial. Circulation 2005;111:2233-40.

\section{Chan 2005}

Chan FKL, Ching JYL, Hung LCT, Wong VWS, Leun VKS, Kung NNS, et al. Clopidogrel versus aspirin and esomeprazole to prevent recurrent ulcer bleeding. New England Journal of Medicine 2005;352(3):238-44.

\section{CHARISMA 2006}

Bhatt DL, Fox KA, Hacke W, Berger PB, Black HR, Boden WE, et al. Clopidogrel and aspirin versus aspirin alone for the prevention of atherothrombotic events. New England Journal of Medicine 2006;354:1706-17.

\section{ESPRIT}

The ESPRIT Study Group. Aspirin plus dipyridamole versus aspirin alone after cerebral ischaemia of arterial origin (ESPRIT): randomised controlled trial. Lancet 2006;367:1665-73.

\section{ESPS-2}

Diener HC, Cunha L, Forbes C, Sivenius J, Smets P, Lowenthal A. European secondary prevention study 2: dipyridamole and acetylsalicylic acid in the secondary prevention of stroke. Journal of Neurological Sciences 1996;143:1-13.

\section{FASTER}

Kennedy J, Hill MD, Ryckborst KJ, Eliasziw M, Demchuk AM, Buchan AM, FASTER Investigators. Fast assessment of stroke and transient ischaemic attack to prevent early recurrence (FASTER): a randomised controlled pilot trial. Lancet Neurology 2007;6:961-9.

\section{Hebert 1993}

Hebert JM, Frechel D, Vallee E. Clopidogrel, a novel antiplatelet and antithrombotic agent. Cardiovascular Drug Reviews 1993;11:180-93.

\section{Ho 2009}

Ho PM, Maddox TM, Wang L, Fihn SD, Jesse RL, Peterson ED, et al. Risk of adverse outcomes associated with concomitant use of clopidogrel and proton pump inhibitors following acute coronary syndrome. JAMA 2009;301:937-44.

\section{Lanas 2007}

Lanas A, García-Rodríguez L, Arroyo MT, Bujanda L, Gomollón F, Forné $\mathrm{M}$, et al. Effect of antisecretory drugs and nitrates on the risk of ulcer bleeding associated with nonsteroidal antiinflammatory drugs, antiplatelet agents, and anticoagulants. American Journal of Gastroenterology 2007;102:507-15. 


\section{MATCH 2004}

Diener HC, Bogousslavsky J, Brass LM, Cimminiello C, Csiba L, Kaste M, et al. Aspirin and clopidogrel compared with clopidogrel alone after recent ischaemic stroke or transient ischaemic attack in high-risk patients (MATCH): randomised, double-blind, placebo-controlled trial. Lancet 2004;364:331-7.

\section{McTavish 1990}

McTavish D, Faulds G, Goa KL. Ticlopidine: an updated review of its pharmacology and therapeutic use in platelet-dependent disorders. Drugs 1990;40:238-59.

\section{Moloney 1993}

Moloney BA. An analysis of the side effects of ticlopidine.. In: Hass WK, Easton JD editor(s). Ticlopidine, Platelets and Vascular Disease. New York: Springer, 1993:117-39.

\section{Müller 2000}

Müller C, Büttner HJ, Petersen J, Roskamm H. A randomized comparison of clopidogrel and aspirin versus ticlopidine and aspirin after the placement of coronary-artery stents. Circulation 2000;101:590-3.

\section{NICE Guidelines}

National Institute for Health and Clinical Excellence. Technology Appraisal 90: Clopidogrel and modified-release dipyridamole in the prevention of occlusive vascular events. http:// www.nice.org.uk/nicemedia/pdf/TA090guidance.pdf 2005.

\section{Patrono 1989}

Patrono C. Aspirin and human platelets: from clinical trials to acetylation of cyclooxygenase and back. Trends in Pharmacological Sciences 1989;10:453-8.

\section{Patrono 1994}

Patrono C. Aspirin as an antiplatelet drug. New England Journal of Medicine 1994;330:1287-94.

\section{PRoFESS}

Sacco RL, Diener H-C, Yusuf S, Cotton D, Ôunpuu S, Lawton WA, et al. Aspirin and extended-release dipyridamole versus clopidogrel for recurrent stroke. New England Journal of Medicine 2008;358:1238-51.

\section{PRoFESS Editorial}

Kent DM, Thaler DE. Stroke prevention - insights from incoherence. New England Journal of Medicine 2008;359:1287-9.

\section{RCP Guidelines}

Royal College of Physicians Intercollegiate Stroke Working Party. National Clinical Guidelines for Stroke. 3rd Edition.
London: Clinical Effectiveness and Evaluation Unit, Royal College of Physicians, 2008.

\section{Sabatine 2005}

Sabatine MS. Something old, something new: beta blockers and clopidogrel in acute myocardial infarction. Lancet 2005;366:1587-9.

\section{SIGN Guidelines}

Scottish Intercollegiate Guidelines Network. Guideline 108. Management of patients with stroke or TIA: assessment, investigation, immediate management and secondary prevention. http://www.sign.ac.uk/pdf/sign108.pdf 2008.

\section{Steinhubl 1999}

Steinhubl SR, Tan WA, Foody JM, Topol EJ, for the EPISTENT Investigators. Incidence and clinical course of thrombotic thrombocytopenic purpura due to ticlopidine following coronary stenting. JAMA 1999;281:806-10.

\section{Torok 1995}

Torok TJ, Holman RC, Chorba TL. Increasing mortality from thrombotic thrombocytopenic purpura in the United States: analysis of national mortality data, 1968-1991. American Journal of Haematology 1995;50:84-90.

\section{TRITON-TIMI 382007}

Wiviott SD, Braunwald E, McCabe CH, Montalescot G, Ruzyllo W, Gottlieb S, et al. Prasugrel versus clopidogrel in patients with acute coronary syndromes. New England Journal of Medicine 2007;357:2001-15.

\section{Zakarija 2004}

Zakarija A, Bandarenko N, Pandey DK, Auerbach A, Raisch DW, Kim B, et al. Clopidogrel-associated TTP: an update of pharmacovigilance efforts conducted by independent researchers, pharmaceutical suppliers, and the Food and Drug Administration. Stroke 2004;35:533-7.

\section{References to other published versions of this review Hankey 2000}

Hankey G, Sudlow CLM, Dunbabin DW. Thienopyridine derivatives (ticlopidine, clopidogrel) versus aspirin for preventing stroke and other serious vascular events in high vascular risk patients. Cochrane Database of Systematic Reviews 2000, Issue 1. [Art. No.: CD001246. DOI: 10.1002/14651858.CD001246]

* Indicates the major publication for the study

\section{CHARACTERISTICS OF STUDIES}

Characteristics of included studies [ordered by year of study]

$\begin{array}{ll}\text { Japanese-B } & \\ \text { Methods } & \begin{array}{l}\mathrm{R}=\text { randomised but method not stated } \\ \mathrm{C}=\text { not stated }\end{array}\end{array}$

Thienopyridine derivatives versus aspirin for preventing stroke and other serious vascular events in high vascular risk patients (Review) 


\begin{tabular}{|c|c|}
\hline Participants & $\begin{array}{l}101 \text { centres in Japan } \\
340 \text { patients randomised; } 1981 \text { to } 1983 \\
\text { Recent (within } 3 \text { months) TIA } \\
\text { Balanced prognostic factors }\end{array}$ \\
\hline Interventions & $\begin{array}{l}\text { Ticlopidine ( } 2 \times 100 \mathrm{mg} \text { tablets) and } 1 \text { placebo tablet versus aspirin }(1 \times 500 \mathrm{mg} \text { tablet }) \text { and } 2 \text { placebo } \\
\text { tablets } \\
\text { Mean duration of treatment: } 17 \text { months }\end{array}$ \\
\hline Outcomes & Frequency, duration and severity of TIA, RIND, cerebral and MI \\
\hline Notes & $\begin{array}{l}\text { Co: "About half" discontinued medication before completing the 12-month follow up (due to expiry of } \\
\text { study period for patients who were entered late, lost to follow up, and adverse reactions) } \\
59 \text { patients ( } 34 \text { ticlopidine, } 25 \text { aspirin) were not included in analysis of efficacy; } 6 \text { patients ( } 5 \text { ticlopidine } \\
\text { and } 1 \text { aspirin) excluded post-randomisation because of questionable diagnosis of TIA or incorrect med- } \\
\text { ication (the meaning of the latter requires clarification; does it mean that treatment was unblinded?); } \\
39 \text { were not considered to have had a TIA within } 3 \text { months ( } 21 \text { ticlopidine, } 18 \text { aspirin), and } 14 \text { discontin- } \\
\text { ued medication within } 2 \text { weeks after entry ( } 8 \text { ticlopidine, } 6 \text { aspirin) } \\
\text { Follow up: } 12 \text { months }\end{array}$ \\
\hline
\end{tabular}

Schoop 1983

$\begin{array}{ll}\text { Methods } & \mathrm{R}=\text { randomised, but method not stated } \\ \mathrm{C}=\text { not stated } \\ \text { Blinding: described as 'open' (and presumed that neither patients nor investigators blinded) }\end{array}$

\begin{tabular}{ll}
\hline Participants & Single centre, Germany \\
January 1979 to January 1983 \\
Peripheral leg arteriopathy with unilateral femoral artery stenosis or occlusion, or the beginning of \\
stenosis of the femoral or popliteal artery on the side opposed to the occlusion \\
All male (62 men) \\
Ex crit: thrombocytosis, diabetes, pulmonary insufficiency, thyroid dysfunction, severe hepatic or renal \\
insufficiency, malignant hypertension, acute gastric or recurring ulcers, malignant tumours, or long- \\
term treatment with drugs modifying platelet functions
\end{tabular}

\begin{tabular}{ll}
\hline Interventions & Ticlopidine $250 \mathrm{mg}$ twice daily versus aspirin $500 \mathrm{mg} 3$ times daily \\
Duration of Rx: 2 years
\end{tabular}
Duration of Rx: 2 years

\begin{tabular}{ll}
\hline Outcomes & Primary outcome (not included in this review): thrombosis/occlusion of the contralateral femoral \\
& artery \\
& Secondary outcomes (included in this review): death, fatal MI, diarrhoea, nausea and gastric pain, skin \\
& rash
\end{tabular}

Notes

Co: withdrawals on ticlopidine: 8 ( 3 due to adverse drug reaction, 5 other, 0 deaths), withdrawals on aspirin: 23 (11 due to adverse drug reactions, 7 other, 5 deaths)

Follow up: 36 patients ( 23 ticlopidine, 13 aspirin) completed 2 years in the trial, 27 per protocol (17 ticlopidine, 10 aspirin)

62 patients ( 31 ticlopidine, 31 aspirin) were analysed by intention to treat, and 44 patients ( 23 ticlopidine and 21 aspirin) were analysed per protocol, according to the inclusion criteria; the remaining 18 patients ( 8 ticlopidine and 10 aspirin) had bilateral femoral artery stenosis 


Participants
56 centres in USA and Canada
TIA, RIND, or minor ischaemic stroke (at least $80 \%$ recovery within 3 weeks) due to presumed
atherothromboembolism
CT scan: $75 \%$ of patients ( $50 \%$ abnormal)
Mean time from qualifying event to treatment: 21 days
Mean age: 63 years
Gender: $64 \%$ male
Race: $80 \%$ white
Comparability of groups: age, gender, vascular risk factors
Ex crit: < 40 years; women of childbearing potential; history of carotid artery surgery or a moderate-to-
major stroke <3 months before a qualifying event; symptoms due to migraine, cardiogenic embolism,
or haematological disorders; history of peptic ulcer, upper GI bleeding; life-threatening disease such as
cancer; aspirin hypersensitivity or intolerance; aspirin or anticoagulant use required

\section{Sadowski 1995}

\begin{tabular}{ll}
\hline Methods & $\begin{array}{l}\mathrm{R}=\text { randomised but method not stated } \\
\mathrm{C}=\text { not stated } \\
\text { Blinding = double blinded }\end{array}$ \\
\hline Participants & $\begin{array}{l}320 \text { patients } \\
\text { Unstable angina type increasing angina (204) or rest angina (116) }\end{array}$ \\
\hline Interventions & Ticlopidine and metaprolol, ticlopidine and gallopamil, aspirin and metaprolol, aspirin and gallopamil \\
\hline Outcomes & Angina recurrence, Ml and death \\
\hline Notes & Duration of follow up: 3 months \\
\hline
\end{tabular}

\section{CAPRIE}

\begin{tabular}{|c|c|}
\hline Methods & $\begin{array}{l}\mathrm{R}=\text { computer-generated balanced blocks of } 4 \text { with random allocation to indistinguishable blister packs } \\
\text { containing either clopidogrel plus aspirin placebo or aspirin plus clopidogrel placebo tablets, stratified } \\
\text { by clinical centre and the } 3 \text { disease subgroups; the initial supply of study drug had a sealed treatment } \\
\text { code label attached which once opened could not be resealed } \\
C=\text { access to code restricted to Independent Statistical Centre, Chairman of Safety and Efficacy Moni- } \\
\text { toring Committee and } 2 \text { companies responsible for preparing the study drugs }\end{array}$ \\
\hline
\end{tabular}


CAPRIE (Continued)

Blinding: patients, clinicians (testing and assessing)

Results available for all patients

\section{Participants}

384 centres in USA, Europe, and Australia

19,185 patients randomised, 1992 to 1995

6431 patients with recent ischaemic stroke (including retinal and lacunar infarction) likely to be of atherothrombotic origin 1 week to 6 months before randomisation; 6302 patients with recent $\mathrm{Ml}<35$ days before randomisation; and 6452 patients with atherosclerotic peripheral arterial disease manifest as intermittent claudication and either ankle/arm systolic BP ratio $<0.85$ in either leg at rest or previous peripheral artery surgery/angioplasty

Mean age: 62.5 years

Gender: $72 \%$ male

Race: 95\% white

Comparability of groups: age, gender, and vascular risk factors

Ex. crit: $<21$ years, severe cerebral deficit, carotid endarterectomy after qualifying stroke, qualifying stroke induced by carotid endarterectomy or angiography, poor life expectancy (<3 years), uncontrolled hypertension, contraindications to study drugs (aspirin sensitivity, bleeding diathesis, other antiplatelet drugs), women of childbearing potential not using contraception

\begin{tabular}{|c|c|}
\hline Interventions & Clopidogrel 75 mg once daily versus aspirin 325 mg once daily \\
\hline Outcomes & $\begin{array}{l}\text { Primary: ischaemic stroke, MI, or vascular death } \\
\text { Secondary: ischaemic stroke, MI, leg amputation, or vascular death; vascular death; stroke, MI or death } \\
\text { from any cause; death from any cause }\end{array}$ \\
\hline Notes & $\begin{array}{l}\text { Co: mean compliance was } 91 \% \text { for clopidogrel and also for aspirin } \\
86 \text { patients }(0.4 \%) \text { never took any study drug ( } 46 \text { in clopidogrel group and } 40 \text { in aspirin group) } \\
4059 \text { patients ( } 21.2 \%) \text { permanently discontinued study drug early for reasons other than occurrence of } \\
\text { an outcome event; } 21.3 \% \text { in the clopidogrel and } 21.1 \% \text { in the aspirin group } \\
\text { Reasons for stopping drug early were: adverse events }(11.4 \%) \text {, withdrawn consent }(4.7 \%) \text {, contraindi- } \\
\text { cated medications ( } 2.4 \%) \text {, non-compliance }(1.8 \%) \text {, and other }(0.8 \%) \\
\text { Duration of follow up: mean follow up was } 1.91 \text { years } \\
\text { Lost to follow up: } 42 \text { patients ( } 0.22 \%) \text {, ( } 22 \text { in clopidogrel and } 20 \text { in aspirin groups) but were included in } \\
\text { the analyses with their follow up censored at the time of last contact }\end{array}$ \\
\hline
\end{tabular}

$\begin{array}{ll}\text { Methods } & \mathrm{R}=\text { randomisation sequence in blocks varying randomly in size from } 2 \text { to } 8 \\ & \text { Ratio of those receiving ticlopidine to aspirin was } 1: 1 \\ & \text { Study participants registered by local study site personnel via a dedicated automated telephone regis- } \\ \text { tration system } & \mathrm{C}=\text { access to code restricted to chief study statistician } \\ \text { Blinding: patients and all study personnel with exception of study statistician } \\ \text { Ticlopidine and aspirin tablets dispensed with physically identical placebo from plastic bottles }\end{array}$

\section{Participants}

\section{2 centres in the USA}

1809 patients randomised, 1995 to 2001

Black (African-American race, 29 to 85 years of age, noncardioembolic ischaemia stroke onset 7 to 90 days before randomisation

CT or MRI image consistent with cerebral infarct and measurable neurological deficit correlating with infarct

Mean age: 61 years

Gender: $47 \%$ male

Race: $100 \%$ Black

Comparability of groups: age, gender and vascular risk factors

Ex crit: TIA, SAH, cardiac source embolism, iatrogenic stroke, non-atherosclerotic stroke, post-operative stroke, carotid endarterectomy as primary treatment measure, mean arterial blood pressure $>130$ $\mathrm{mmHg}$ on 3 consecutive days, modified Barthel index $<10$, dementia or neurodegenerative disease, se-

Thienopyridine derivatives versus aspirin for preventing stroke and other serious vascular events in high vascular risk patients (Review) 16 Copyright $\odot 2010$ The Cochrane Collaboration. Published by John Wiley \& Sons, Ltd. 
AAASPS (Continued)

vere co-morbid condition such as cancer, allergy or insensitivity to study drugs, woman of childbearing potential, GI tract bleeding, bleeding diathesis, platelet or other haematological abnormality, haematuria, positive faecal occult blood test, prolonged prothrombin time or partial thromboplastin time,

blood urea $>40 \mathrm{mg} / \mathrm{dL}$, serum creatinine $>2 \mathrm{mg} / \mathrm{dL}$, thrombocytopenia, neutropenia, liver function tests

$>2$ times upper limit of normal

\begin{tabular}{|c|c|}
\hline Interventions & Ticlopidine $250 \mathrm{mg}$ twice daily versus aspirin $325 \mathrm{mg}$ twice daily \\
\hline Outcomes & $\begin{array}{l}\text { Primary: composite of recurrent stroke, MI or vascular death } \\
\text { Secondary: stroke, MI, vascular death, any death }\end{array}$ \\
\hline Notes & $\begin{array}{l}\text { Co: median compliance was } 90 \% \text { for ticlopidine and } 92 \% \text { for aspirin } \\
\text { Duration of follow up: mean follow up was } 1.54 \text { years } \\
\text { Lost to follow up: } 137 \text { patients }(15.2 \%) \text { in the ticlopidine group and } 121(13.3 \%) \text { in aspirin group were ei- } \\
\text { ther lost to follow-up or voluntarily withdrew } \\
\text { Most of these were due to voluntary withdrawals but it is uncertain whether follow-up data was avail- } \\
\text { able for these patients }\end{array}$ \\
\hline
\end{tabular}

De Lucia 2000

\begin{tabular}{ll}
\hline Methods & $\begin{array}{l}\mathrm{R}=\text { randomised but method not stated } \\
\mathrm{C}=\text { not stated } \\
\text { Blinding = double blind but methods not stated }\end{array}$ \\
\hline Participants & $\begin{array}{l}100 \text { patients randomised } \\
\text { Hx TIA, }<45 \text { years old } \\
\text { Mean age: } 36 \text { years } \\
\text { Gender: } 72 \% \text { male }\end{array}$ \\
\hline Interventions & Aspirin 100 mg daily versus ticlopidine 500 mg daily \\
\hline Outcomes & Ischaemic stroke, MI, cancer and all causes of vascular death \\
\hline Notes & No data available \\
\hline
\end{tabular}

\section{Li 2000}

$\begin{array}{ll}\text { Methods } & \mathrm{R}=\text { randomised but method not stated } \\ \mathrm{C}=\text { not stated } \\ \text { Blinding = described as 'open' }\end{array}$

\begin{tabular}{ll}
\hline Participants & 329 patients randomised \\
Inclusion criteria according to Chinese standards of acute cerebral vascular disease classification and \\
diagnosis \\
Mean age: 64 years \\
Gender: $70 \%$ male
\end{tabular}

\begin{tabular}{ll}
\hline Interventions & Aspirin $100 \mathrm{mg}$ daily versus ticlopidine $500 \mathrm{mg}$ daily \\
\hline Outcomes & Primary: stroke and MI \\
\hline Notes & $\begin{array}{l}\text { Co: no information available } \\
\text { Duration of follow up: } 6 \text { to } 18 \text { months } \\
\text { Lost to follow up: } 21 \text { in the ticlopidine and } 10 \text { in aspirin group; they were not included in the analyses }\end{array}$
\end{tabular}

Thienopyridine derivatives versus aspirin for preventing stroke and other serious vascular events in high vascular risk patients (Review) 
Zhu 2001

\begin{tabular}{ll}
\hline Methods & $\begin{array}{l}\mathrm{R}=\text { randomised but method not stated } \\
\mathrm{C}=\text { not stated } \\
\text { Not blinded }\end{array}$ \\
\hline Participants & $\begin{array}{l}181 \text { patients randomised } \\
\text { Inclusion criteria according to Chinese stroke diagnosis standards } \\
\text { Ex crit: Intolerance to antiplatelets or anticoagulant drugs, presence of bleeding disorder, low platelet } \\
\text { count, cardiac source embolism, infarction induced by tumour, haemorrhagic stroke }\end{array}$ \\
\hline Interventions & Aspirin (3 doses: $25 \mathrm{mg}, 50 \mathrm{mg}, 100 \mathrm{mg}$ ) versus ticlopidine $250 \mathrm{mg}$ daily versus lumbrokinase 600 mg \\
\hline Outcomes & Primary: recurrent stroke \\
\hline Notes & $\begin{array}{l}\text { Co: No information available } \\
\text { Duration of follow up: } 12 \text { months } \\
\text { Lost to follow up: } 16 \text { patients were not included in the analyses; of these } 6 \text { were lost to follow up, } 7 \text { suf- } \\
\text { fered brain haemorrhage and } 3 \text { had low white cell count; the number in each treatment arm was not } \\
\text { available }\end{array}$ \\
\hline
\end{tabular}

STAMI

$\begin{array}{ll}\text { Methods } & \mathrm{R}=\text { randomised but method not stated } \\ \mathrm{C}=\text { not stated } & \\ & \text { Blinding: patients, clinicians and outcome assessors } \\ & \text { Patients allocated to indistinguishable blister packs containing either ticlopidine or aspirin }\end{array}$

Pulticentre, number not stated
Participants
> 18 years old with MI (treated with thrombolytic therapy) $\leq 30$ days before randomisation
Mean age: 59 years
Gender: $84 \%$ male
Race: not stated
Comparibility of groups: age, gender, vascular risk factors
Ex crit: contraindications to the study drugs including haemopoietic or haemostatic disorders, Hx
thrombocytopenia, leucopenia or peptic ulcer, need for oral anticoagulant therapy, scheduled major
or bypass surgery, severe co-morbidity likely to limit life-expectancy, uncontrolled hypertension, geo-
graphic or other factors likely to make participation impractical

\begin{tabular}{|c|c|}
\hline Interventions & Ticlopidine $250 \mathrm{mg}$ twice daily versus aspirin $80 \mathrm{mg}$ twice daily \\
\hline Outcomes & $\begin{array}{l}\text { Primary: non-fatal MI, non-fatal stroke, angina with objective evidence of cardiac ischaemia, vascular } \\
\text { death } \\
\text { Secondary: vascular death, non-vascular death, non-fatal stroke, non-fatal MI, angina }\end{array}$ \\
\hline Notes & $\begin{array}{l}\text { Co: } 333(22.6 \%) \text { patients permanently discontinued the study drug early; } 152 \text { in the aspirin group and } \\
181 \text { in the ticlopidine group } \\
\text { Reasons for stopping the treatment early were adverse events ( } 35 \text { in aspirin group and } 53 \text { in ticlopidine } \\
\text { group) } \\
\text { Of these, } 26 \text { in the aspirin group and } 21 \text { in the ticlopidine group withdrew because of occurrence of a } \\
\text { primary end point } \\
\text { Duration of follow up: mean follow up was } 6 \text { months } \\
\text { Lost to follow up: } 32(4.4 \%) \text { in the ticlopidine group and } 30(4.1 \%) \text { in the aspirin group }\end{array}$ \\
\hline
\end{tabular}

B: blood pressure

Thienopyridine derivatives versus aspirin for preventing stroke and other serious vascular events in high vascular risk patients (Review) 
C: concealment of allocation

Co: compliance

Ex crit: exclusion criteria

Gl: gastrointestinal

$\mathrm{Hx}$ : history

MI: myocardial infarction

R: randomisation method

RIND: reversible ischaemic neurological deficit

Rx: treatment

SAH: subarachnoid haemorrhage

TIA: transient ischaemic attack

Characteristics of excluded studies [ordered by study ID]

\begin{tabular}{|c|c|}
\hline Study & Reason for exclusion \\
\hline Abe 1981 & Outcome measure (platelet aggregation) was not a serious vascular event \\
\hline Akyuz 1999 & Non-randomised and outcome measure (platelet aggregation) was not a serious vascular event \\
\hline Apollonio 1989 & $\begin{array}{l}\text { Non-randomised } \\
\text { Comparison confounded for question of interest (ticlopidine and pentoxifylline versus aspirin, } \\
\text { dipyridamole and buflomedil versus buflomedil) }\end{array}$ \\
\hline Aramendi 1998 & Non-randomised \\
\hline Bergamasco 1997 & Ticlopidine compared with indobufen, not aspirin \\
\hline Cooke 2006 & Outcome measures (platelet function) were not serious vascular events; follow up only 10 days \\
\hline Dorr 2004 & $\begin{array}{l}\text { Outcome measures (platelet glycoprotein expression and aggregation) were not serious vascular } \\
\text { events }\end{array}$ \\
\hline Droste 1996 & $\begin{array}{l}\text { Duration of treatment was only } 2 \text { weeks (with cross over to } 2 \text { weeks of treatment with the alterna- } \\
\text { tive agent), and outcomes (haematological parameters, and asymptomatic cerebral emboli detect- } \\
\text { ed by transcranial doppler) were not important vascular events }\end{array}$ \\
\hline Eder 2007 & Outcome measure (platelet function) not serious vascular events \\
\hline Fork 2000 & $\begin{array}{l}\text { Outcome measure (detection of macroscopic differences in the gastric mucosa) was not a serious } \\
\text { vascular event }\end{array}$ \\
\hline Jagroop 2004 & Outcome measures (platelet function indices) were not serious vascular events \\
\hline Kindsvater 2003 & Outome measure exercise tolerance, not serious vascular events; follow up several hours only \\
\hline KTS 1999 & $\begin{array}{l}\text { Uncertain if randomised } \\
\text { Presumably healthy participants }\end{array}$ \\
\hline Lim 2004 & Primary outcome measure (platelet aggregation) was not a serious vascular event \\
\hline Nomura 1996 & Outcome measure (platelet aggregation) was not a serious vascular event \\
\hline Ozalp 1997 & Uncertain if randomised; outcome measure (plasma fibrinogen) not a serious vascular event \\
\hline Rebrov 2001 & Outcome measures (haemostasis and platelet aggregation) were not serious vascular events \\
\hline Rey 1996 & Not randomised \\
\hline
\end{tabular}

Thienopyridine derivatives versus aspirin for preventing stroke and other serious vascular events in high vascular risk patients (Review) 


\begin{tabular}{ll}
\hline Study & Reason for exclusion \\
\hline Rupprecht 1998 & Outcome measure (platelet aggregation) not serious vascular events; follow up for 14 days only \\
\hline Singh 1999 & Outcome measure (platelet aggregation) not serious outcome events; follow up 10 days only \\
\hline Tokyo 1993 & Comparison confounded for question of interest (ticlopidine versus ticlopidine plus aspirin) \\
\hline Vyshlov 2000 & Outcome measures (platelet aggregation) not serious vascular events; follow up only 21 days \\
\hline Woodward 2004 & Outcome measures (clotting factors and C reactive protein) were not serious vascular events \\
\hline Zucca 1992 & $\begin{array}{l}\text { Not randomised } \\
\text { Outcome measure (carotid restenosis demonstrated by carotid doppler) not a serious vascular } \\
\text { event }\end{array}$ \\
\hline
\end{tabular}

Characteristics of studies awaiting assessment [ordered by study ID]

\section{Bokarev 1998}

\begin{tabular}{ll}
\hline Methods & Uncertain \\
\hline Participants & Patients with unstable angina \\
\hline Interventions & Aspirin versus ticlopidine \\
\hline Outcomes & Uncertain \\
\hline Notes & Full paper awaited \\
\hline
\end{tabular}

WATCH

$\begin{array}{ll}\text { Methods } & \text { Randomised = centrally generated randomisation sequence for each site using varying block sizes } \\ \text { of } 3 \text { or } 6 & \\ \text { Concealement of treatment allocation - centralised, telephone randomisation } & \text { Blinding: of patients and clinicians to aspirin versus clopidogrel (warfarin arm open label); of end- } \\ \text { point adjudication committee to allocated treatment } \\ \text { Results available for all patients }\end{array}$

Participants 1587 patients (523 aspirin, 524 clopidogrel) with symptomatic heart failure, in sinus rhythm, with
left ventricular ejection fraction $\leq 35 \%$
Mean age: 63 years
Gender: $85 \%$ male
Race: $77 \%$ white; $13 \%$ black
Cause of heart failure ischaemic heart disease in $73 \%$
Comparibility of groups: age, gender, cause and duration of heart failure, medications, vascular
risk factors
Ex crit: contraindications to or specific indications for study drugs, imminent procedures necessi-
tating withdrawal or use of study drugs, heart failure from correctable causes, serious co-morbidity
likely to limit life-expectancy, conditions likely to interfere with protocol adherence


WATCH (Continued)

Secondary: components of primary outcome, hospitalisations for heart failure

Notes Trial stopped early due to slow enrolment

Planned sample size originally 4500 patients

Compliance: on the basis of returned tablet counts, $80 \%$ of prescribed aspirin and clopidogrel (or matching placebo) tablets taken

$100(19 \%)$ aspirin and $102(19 \%)$ clopidogrel patients discontinued study drug early

Duration of follow up: mean follow up was 1.9 years

Lost to follow up: aspirin $24(5 \%), 6(1 \%)$ for vital status; clopidogrel 30 (6\%), 8 (2\%) for vital status

Ex crit: exclusion criteria

INR: International normalized ratio

MI: myocardial infarction

Characteristics of ongoing studies [ordered by study ID]

\section{ASCET}

\begin{tabular}{ll}
\hline Trial name or title & ASpirin non-responsiveness and Clopidogrel Endpoint Trial (ASCET) \\
\hline Methods & Randomised, open label \\
\hline Participants & 1000 patients with documented coronary heart disease \\
\hline Interventions & Continued treatment with aspirin 160 mg daily versus or change to clopidogrel 75 mg daily \\
\hline Outcomes & Composite of unstable angina, myocardial infarction, stroke or death \\
\hline Starting date & April 2003 \\
\hline Contact information & http://clinicaltrials.gov/ct2/show/NCT00222261 \\
\hline Notes & \\
\hline
\end{tabular}

\section{DATA AND ANALYSES}

\section{Comparison 1. Thienopyridine versus aspirin in high vascular risk patients}

\begin{tabular}{|c|c|c|c|c|}
\hline Outcome or subgroup title & $\begin{array}{l}\text { No. of } \\
\text { studies }\end{array}$ & $\begin{array}{l}\text { No. of } \\
\text { partici- } \\
\text { pants }\end{array}$ & Statistical method & Effect size \\
\hline $\begin{array}{l}1 \text { Stroke, MI or vascular death during follow } \\
\text { up }\end{array}$ & 7 & 26255 & $\begin{array}{l}\text { Peto Odds Ratio (Peto, Fixed, 95\% } \\
\mathrm{Cl} \text { ) }\end{array}$ & $0.92[0.85,0.99]$ \\
\hline $\begin{array}{l}2 \text { Stroke, MI or vascular death (thienopyri- } \\
\text { dine subgroups) }\end{array}$ & 7 & 26255 & $\begin{array}{l}\text { Peto Odds Ratio (Peto, Fixed, 95\% } \\
\mathrm{Cl} \text { ) }\end{array}$ & $0.92[0.85,0.99]$ \\
\hline 2.1 Ticlopidine versus aspirin & 6 & 7070 & $\begin{array}{l}\text { Peto Odds Ratio (Peto, Fixed, 95\% } \\
\mathrm{Cl} \text { ) }\end{array}$ & $0.94[0.82,1.07]$ \\
\hline 2.2 Clopidogrel versus aspirin & 1 & 19185 & $\begin{array}{l}\text { Peto Odds Ratio (Peto, Fixed, 95\% } \\
\mathrm{Cl} \text { ) }\end{array}$ & $0.91[0.83,0.99]$ \\
\hline
\end{tabular}

Thienopyridine derivatives versus aspirin for preventing stroke and other serious vascular events in high vascular risk patients (Review) 


\begin{tabular}{|c|c|c|c|c|}
\hline Outcome or subgroup title & $\begin{array}{l}\text { No. of } \\
\text { studies }\end{array}$ & $\begin{array}{l}\text { No. of } \\
\text { partici- } \\
\text { pants }\end{array}$ & Statistical method & Effect size \\
\hline 3 Stroke (of all types) during follow up & 7 & 26244 & $\begin{array}{l}\text { Peto Odds Ratio (Peto, Fixed, 95\% } \\
\mathrm{Cl} \text { ) }\end{array}$ & $0.91[0.82,1.01]$ \\
\hline $\begin{array}{l}4 \text { Ischaemic/unknown stroke during follow } \\
\text { up }\end{array}$ & 5 & 22778 & $\begin{array}{l}\text { Peto Odds Ratio (Peto, Fixed, 95\% } \\
\mathrm{Cl} \text { ) }\end{array}$ & $0.89[0.79,0.99]$ \\
\hline $\begin{array}{l}5 \text { Haemorrhagic stroke (symptomatic in- } \\
\text { tracranial haemorrhage) during follow up }\end{array}$ & 4 & 22645 & $\begin{array}{l}\text { Peto Odds Ratio (Peto, Fixed, 95\% } \\
\mathrm{Cl} \text { ) }\end{array}$ & $0.89[0.59,1.35]$ \\
\hline $\begin{array}{l}6 \text { Myocardial infarction (MI) during follow } \\
\text { up }\end{array}$ & 7 & 26244 & $\begin{array}{l}\text { Peto Odds Ratio (Peto, Fixed, 95\% } \\
\mathrm{Cl} \text { ) }\end{array}$ & $0.89[0.78,1.02]$ \\
\hline 7 Vascular death during follow up & 7 & 26255 & $\begin{array}{l}\text { Peto Odds Ratio (Peto, Fixed, 95\% } \\
\mathrm{Cl} \text { ) }\end{array}$ & $0.95[0.84,1.07]$ \\
\hline 8 Death from any cause during follow up & 7 & 26255 & $\begin{array}{l}\text { Peto Odds Ratio (Peto, Fixed, 95\% } \\
\mathrm{Cl} \text { ) }\end{array}$ & $0.96[0.87,1.06]$ \\
\hline $\begin{array}{l}9 \text { Extracranial haemorrhage during follow } \\
\text { up }\end{array}$ & 4 & & $\begin{array}{l}\text { Peto Odds Ratio (Peto, Fixed, 95\% } \\
\mathrm{Cl} \text { ) }\end{array}$ & Subtotals only \\
\hline 9.1 Severe & 2 & 19505 & $\begin{array}{l}\text { Peto Odds Ratio (Peto, Fixed, 95\% } \\
\mathrm{Cl} \text { ) }\end{array}$ & $0.98[0.74,1.29]$ \\
\hline 9.2 Any & 3 & 22316 & $\begin{array}{l}\text { Peto Odds Ratio (Peto, Fixed, 95\% } \\
\mathrm{Cl} \text { ) }\end{array}$ & $1.00[0.91,1.09]$ \\
\hline $\begin{array}{l}10 \text { Gastrointestinal haemorrhage during } \\
\text { follow up }\end{array}$ & 4 & & $\begin{array}{l}\text { Peto Odds Ratio (Peto, Fixed, 95\% } \\
\mathrm{Cl} \text { ) }\end{array}$ & Subtotals only \\
\hline 10.1 Severe & 3 & 21056 & $\begin{array}{l}\text { Peto Odds Ratio (Peto, Fixed, 95\% } \\
\mathrm{Cl} \text { ) }\end{array}$ & $0.67[0.47,0.95]$ \\
\hline 10.2 Any & 2 & 22254 & $\begin{array}{l}\text { Peto Odds Ratio (Peto, Fixed, 95\% } \\
\mathrm{Cl} \text { ) }\end{array}$ & $0.71[0.59,0.86]$ \\
\hline $\begin{array}{l}11 \text { Indigestion/nausea/vomiting during fol- } \\
\text { low up }\end{array}$ & 4 & & $\begin{array}{l}\text { Peto Odds Ratio (Peto, Fixed, 95\% } \\
\mathrm{Cl} \text { ) }\end{array}$ & Subtotals only \\
\hline 11.1 Severe & 2 & 20655 & $\begin{array}{l}\text { Peto Odds Ratio (Peto, Fixed, 95\% } \\
\mathrm{Cl} \text { ) }\end{array}$ & $0.80[0.61,1.04]$ \\
\hline 11.2 Any & 4 & 23786 & $\begin{array}{l}\text { Peto Odds Ratio (Peto, Fixed, 95\% } \\
\mathrm{Cl} \text { ) }\end{array}$ & $0.84[0.78,0.90]$ \\
\hline 12 Neutropenia during follow up & 3 & & $\begin{array}{l}\text { Peto Odds Ratio (Peto, Fixed, 95\% } \\
\mathrm{Cl} \text { ) }\end{array}$ & Subtotals only \\
\hline 12.1 Severe & 3 & 24063 & $\begin{array}{l}\text { Peto Odds Ratio (Peto, Fixed, 95\% } \\
\mathrm{Cl} \text { ) }\end{array}$ & $2.02[1.27,3.21]$ \\
\hline 12.2 Any & 2 & 22254 & $\begin{array}{l}\text { Peto Odds Ratio (Peto, Fixed, 95\% } \\
\mathrm{Cl} \text { ) }\end{array}$ & $1.61[1.01,2.55]$ \\
\hline
\end{tabular}




\begin{tabular}{|c|c|c|c|c|}
\hline Outcome or subgroup title & $\begin{array}{l}\text { No. of } \\
\text { studies }\end{array}$ & $\begin{array}{l}\text { No. of } \\
\text { partici- } \\
\text { pants }\end{array}$ & Statistical method & Effect size \\
\hline $\begin{array}{l}13 \text { Any neutropenia (thienopyridine sub- } \\
\text { groups) }\end{array}$ & 2 & & $\begin{array}{l}\text { Peto Odds Ratio (Peto, Fixed, 95\% } \\
\mathrm{Cl} \text { ) }\end{array}$ & Subtotals only \\
\hline 13.1 Ticlopidine versus aspirin & 1 & 3069 & $\begin{array}{l}\text { Peto Odds Ratio (Peto, Fixed, 95\% } \\
\mathrm{Cl} \text { ) }\end{array}$ & $2.72[1.53,4.84]$ \\
\hline 13.2 Clopidogrel versus aspirin & 1 & 19185 & $\begin{array}{l}\text { Peto Odds Ratio (Peto, Fixed, 95\% } \\
\mathrm{Cl} \text { ) }\end{array}$ & $0.63[0.29,1.36]$ \\
\hline 14 Thrombocytopenia during follow up & 3 & & $\begin{array}{l}\text { Peto Odds Ratio (Peto, Fixed, 95\% } \\
\mathrm{Cl} \text { ) }\end{array}$ & Subtotals only \\
\hline 14.1 Severe & 3 & 22464 & $\begin{array}{l}\text { Peto Odds Ratio (Peto, Fixed, 95\% } \\
\mathrm{Cl} \text { ) }\end{array}$ & $1.67[0.86,3.25]$ \\
\hline 14.2 Any & 2 & 20655 & $\begin{array}{l}\text { Peto Odds Ratio (Peto, Fixed, 95\% } \\
\mathrm{Cl} \text { ) }\end{array}$ & $1.04[0.61,1.76]$ \\
\hline $\begin{array}{l}15 \text { Any thrombocytopenia (thienopyridine } \\
\text { subgroups) }\end{array}$ & 2 & & $\begin{array}{l}\text { Peto Odds Ratio (Peto, Fixed, 95\% } \\
\mathrm{Cl} \text { ) }\end{array}$ & Subtotals only \\
\hline 15.1 Ticlopidine versus aspirin & 1 & 1470 & $\begin{array}{l}\text { Peto Odds Ratio (Peto, Fixed, 95\% } \\
\mathrm{Cl} \text { ) }\end{array}$ & $1.50[0.26,8.66]$ \\
\hline 15.2 Clopidogrel versus aspirin & 1 & 19185 & $\begin{array}{l}\text { Peto Odds Ratio (Peto, Fixed, 95\% } \\
\mathrm{Cl})\end{array}$ & $1.00[0.57,1.74]$ \\
\hline 16 Skin rash during follow up & 5 & & $\begin{array}{l}\text { Peto Odds Ratio (Peto, Fixed, 95\% } \\
\mathrm{Cl} \text { ) }\end{array}$ & Subtotals only \\
\hline 16.1 Severe & 1 & 19185 & $\begin{array}{l}\text { Peto Odds Ratio (Peto, Fixed, 95\% } \\
\mathrm{Cl} \text { ) }\end{array}$ & $2.36[1.21,4.57]$ \\
\hline 16.2 Any & 5 & 25595 & $\begin{array}{l}\text { Peto Odds Ratio (Peto, Fixed, 95\% } \\
\mathrm{Cl} \text { ) }\end{array}$ & $1.47[1.32,1.64]$ \\
\hline $\begin{array}{l}17 \text { Any skin rash (thienopyridine sub- } \\
\text { groups) }\end{array}$ & 5 & & $\begin{array}{l}\text { Peto Odds Ratio (Peto, Fixed, 95\% } \\
\mathrm{Cl} \text { ) }\end{array}$ & Subtotals only \\
\hline 17.1 Ticlopidine versus aspirin & 4 & 6410 & $\begin{array}{l}\text { Peto Odds Ratio (Peto, Fixed, 95\% } \\
\mathrm{Cl} \text { ) }\end{array}$ & $2.08[1.66,2.61]$ \\
\hline 17.2 Clopidogrel versus aspirin & 1 & 19185 & $\begin{array}{l}\text { Peto Odds Ratio (Peto, Fixed, 95\% } \\
\mathrm{Cl} \text { ) }\end{array}$ & $1.32[1.17,1.50]$ \\
\hline 18 Diarrhoea during follow up & 5 & & $\begin{array}{l}\text { Peto Odds Ratio (Peto, Fixed, 95\% } \\
\mathrm{Cl} \text { ) }\end{array}$ & Subtotals only \\
\hline 18.1 Severe & 1 & 19185 & $\begin{array}{l}\text { Peto Odds Ratio (Peto, Fixed, 95\% } \\
\mathrm{Cl} \text { ) }\end{array}$ & $1.95[0.98,3.85]$ \\
\hline 18.2 Any & 5 & 25595 & $\begin{array}{l}\text { Peto Odds Ratio (Peto, Fixed, 95\% } \\
\mathrm{Cl} \text { ) }\end{array}$ & $1.63[1.45,1.83]$ \\
\hline
\end{tabular}




\begin{tabular}{lllll}
\hline Outcome or subgroup title & $\begin{array}{l}\text { No. of } \\
\text { studies }\end{array}$ & $\begin{array}{l}\text { No. of } \\
\text { partici- } \\
\text { pants }\end{array}$ & Statistical method & Effect size \\
\hline $\begin{array}{l}19 \text { Any diarrhoea (thienopyridine sub- } \\
\text { groups) }\end{array}$ & 5 & & $\begin{array}{l}\text { Peto Odds Ratio (Peto, Fixed, 95\% } \\
\text { Cl) }\end{array}$ & Subtotals only \\
\hline $\begin{array}{llll}19.1 \text { Ticlopidine versus aspirin } \\
\text { 19.2 Clopidogrel versus aspirin }\end{array}$ & 4 & 6410 & $\begin{array}{l}\text { Peto Odds Ratio (Peto, Fixed, 95\% } \\
\text { Cl) }\end{array}$ & $2.28[1.89,2.77]$ \\
\hline
\end{tabular}

Analysis 1.1. Comparison 1 Thienopyridine versus aspirin in high vascular risk patients, Outcome 1 Stroke, MI or vascular death during follow up.

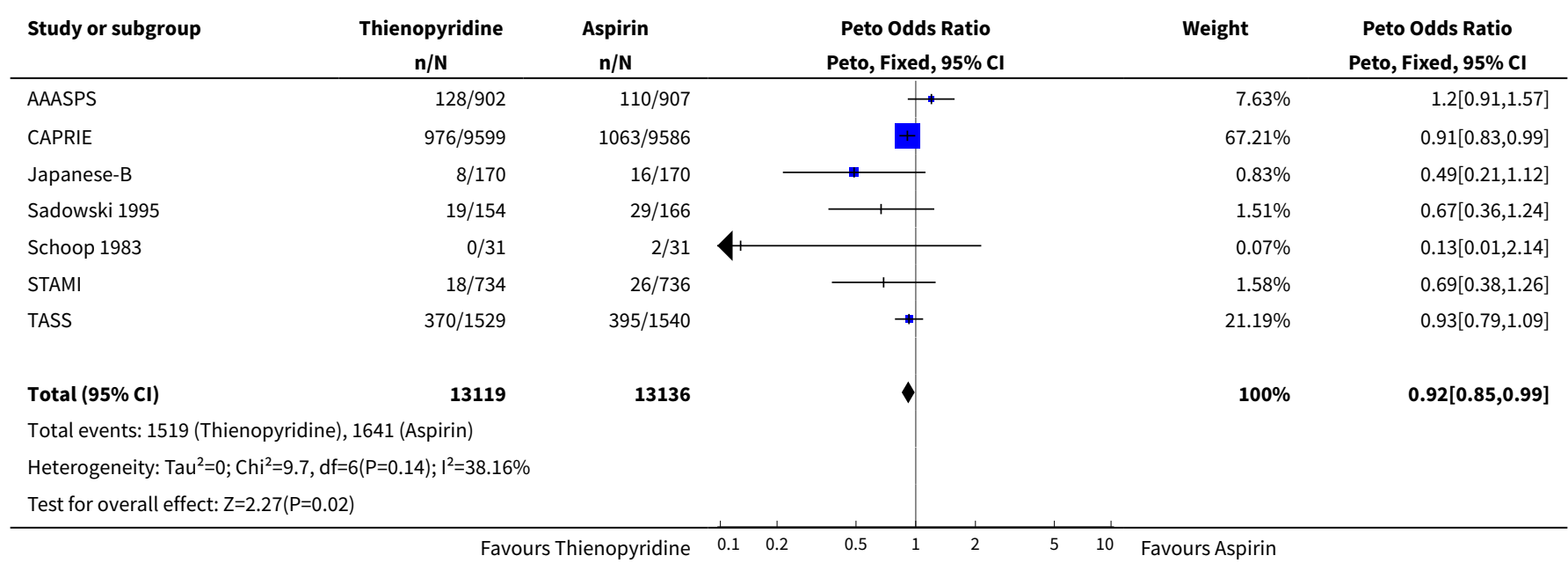

Analysis 1.2. Comparison 1 Thienopyridine versus aspirin in high vascular risk patients, Outcome 2 Stroke, MI or vascular death (thienopyridine subgroups).

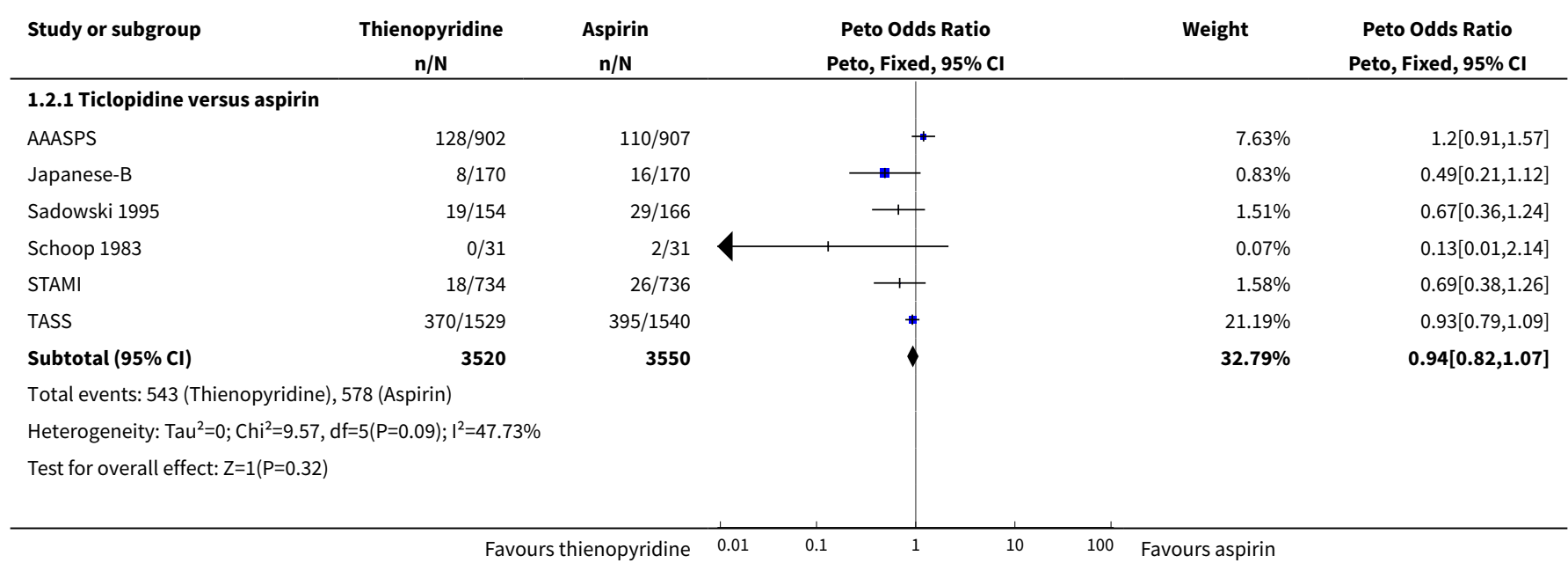




\begin{tabular}{|c|c|c|c|c|c|}
\hline Study or subgroup & $\begin{array}{c}\text { Thienopyridine } \\
\mathrm{n} / \mathrm{N}\end{array}$ & $\begin{array}{c}\text { Aspirin } \\
n / N\end{array}$ & $\begin{array}{c}\text { Peto Odds Ratio } \\
\text { Peto, Fixed, } 95 \% \mathrm{Cl}\end{array}$ & Weight & $\begin{array}{c}\text { Peto Odds Ratio } \\
\text { Peto, Fixed, } 95 \% \mathrm{Cl}\end{array}$ \\
\hline \multicolumn{6}{|c|}{ 1.2.2 Clopidogrel versus aspirin } \\
\hline CAPRIE & $976 / 9599$ & $1063 / 9586$ & & $67.21 \%$ & $0.91[0.83,0.99]$ \\
\hline Subtotal $(95 \% \mathrm{Cl})$ & 9599 & 9586 & 1 & $67.21 \%$ & $0.91[0.83,0.99]$ \\
\hline \multicolumn{6}{|c|}{ Total events: 976 (Thienopyridine), 1063 (Aspirin) } \\
\hline \multicolumn{6}{|c|}{ Heterogeneity: Not applicable } \\
\hline \multicolumn{6}{|c|}{ Test for overall effect: $Z=2.07(P=0.04)$} \\
\hline Total $(95 \% \mathrm{Cl})$ & 13119 & 13136 & 1 & $100 \%$ & $0.92[0.85,0.99]$ \\
\hline \multicolumn{6}{|c|}{ Total events: 1519 (Thienopyridine), 1641 (Aspirin) } \\
\hline \multicolumn{6}{|c|}{ Heterogeneity: $\mathrm{Tau}^{2}=0 ; \mathrm{Chi}^{2}=9.7, \mathrm{df}=6(\mathrm{P}=0.14) ; \mathrm{I}^{2}=38.16 \%$} \\
\hline \multicolumn{6}{|c|}{ Test for overall effect: $\mathrm{Z}=2.27(\mathrm{P}=0.02)$} \\
\hline \multicolumn{6}{|c|}{ Test for subgroup differences: $\mathrm{Chi}^{2}=0.14, \mathrm{df}=1(\mathrm{P}=0.71), \mathrm{I}^{2}=0 \%$} \\
\hline & & enopyridine & 0.1 & 100 Favours aspirin & \\
\hline
\end{tabular}

Analysis 1.3. Comparison 1 Thienopyridine versus aspirin in high vascular risk patients, Outcome 3 Stroke (of all types) during follow up.

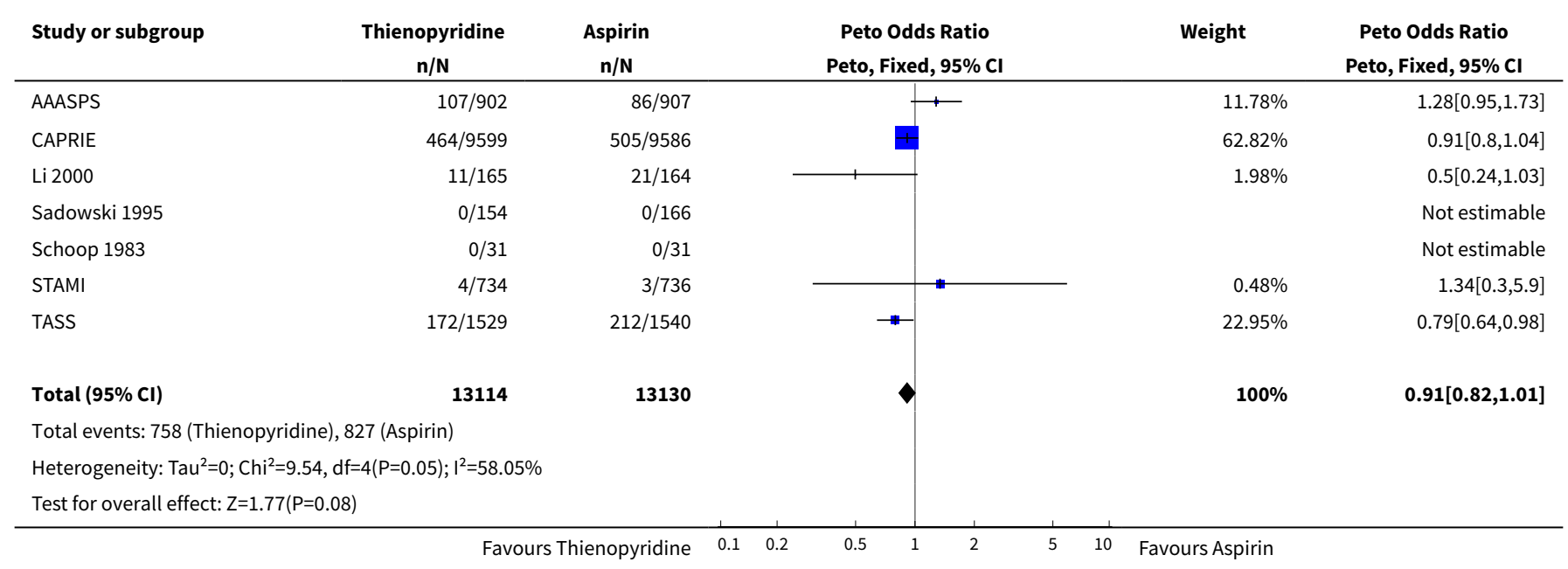

\section{Analysis 1.4. Comparison 1 Thienopyridine versus aspirin in high vascular risk patients, Outcome 4 Ischaemic/unknown stroke during follow up.}

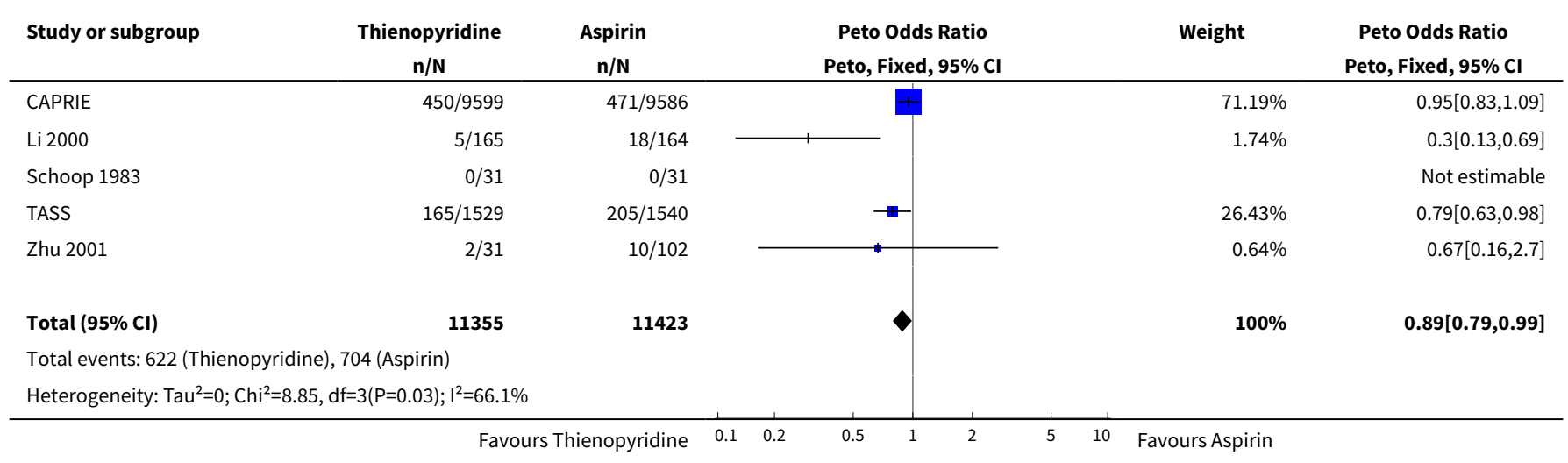




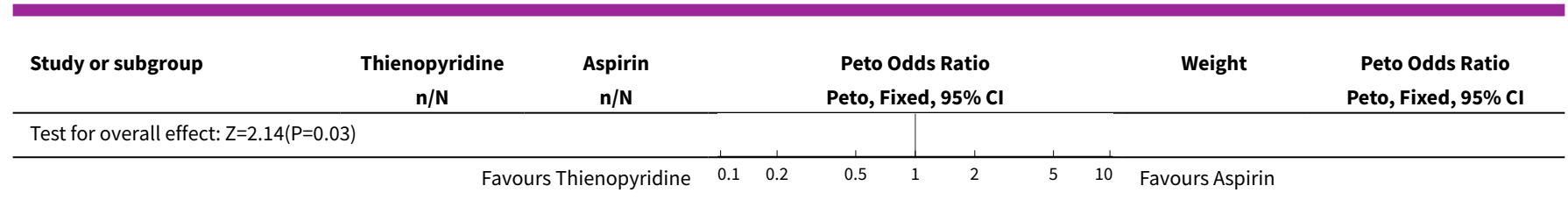

Analysis 1.5. Comparison 1 Thienopyridine versus aspirin in high vascular risk patients, Outcome 5 Haemorrhagic stroke (symptomatic intracranial haemorrhage) during follow up.

\begin{tabular}{|c|c|c|c|c|c|}
\hline Study or subgroup & $\begin{array}{c}\text { Thienopyridine } \\
\mathrm{n} / \mathrm{N}\end{array}$ & $\begin{array}{c}\text { Aspirin } \\
n / N\end{array}$ & $\begin{array}{c}\text { Peto Odds Ratio } \\
\text { Peto, Fixed, } 95 \% \mathrm{CI}\end{array}$ & Weight & $\begin{array}{c}\text { Peto Odds Ratio } \\
\text { Peto, Fixed, 95\% Cl }\end{array}$ \\
\hline CAPRIE & $30 / 9599$ & $38 / 9586$ & +1 & $74.89 \%$ & $0.79[0.49,1.27]$ \\
\hline Japanese-B & $0 / 31$ & $0 / 31$ & & & Not estimable \\
\hline Li 2000 & $6 / 165$ & $3 / 164$ & & $9.7 \%$ & $1.97[0.52,7.39]$ \\
\hline TASS & $7 / 1529$ & $7 / 1540$ & - I & $15.41 \%$ & $1.01[0.35,2.88]$ \\
\hline Total $(95 \% \mathrm{Cl})$ & 11324 & 11321 & & $100 \%$ & $0.89[0.59,1.35]$ \\
\hline \multicolumn{6}{|c|}{ Total events: 43 (Thienopyridine), 48 (Aspirin) } \\
\hline \multicolumn{6}{|c|}{ Heterogeneity: $\mathrm{Tau}^{2}=0 ; \mathrm{Chi}^{2}=1.68, \mathrm{df}=2(\mathrm{P}=0.43) ; \mathrm{I}^{2}=0 \%$} \\
\hline Test for overall effec & & & & & \\
\hline
\end{tabular}

Analysis 1.6. Comparison 1 Thienopyridine versus aspirin in high vascular risk patients, Outcome 6 Myocardial infarction (MI) during follow up.

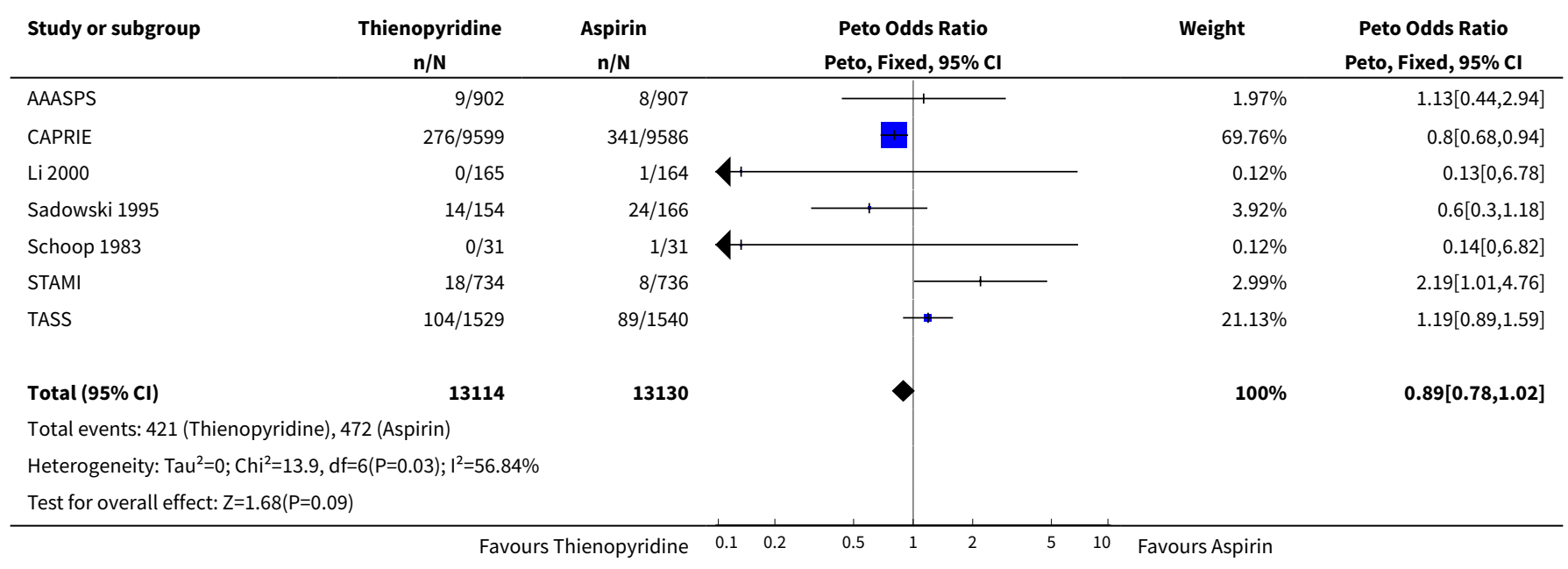

Analysis 1.7. Comparison 1 Thienopyridine versus aspirin in high vascular risk patients, Outcome 7 Vascular death during follow up.

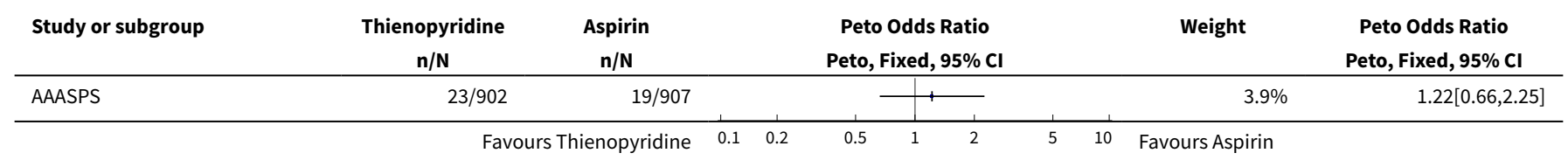




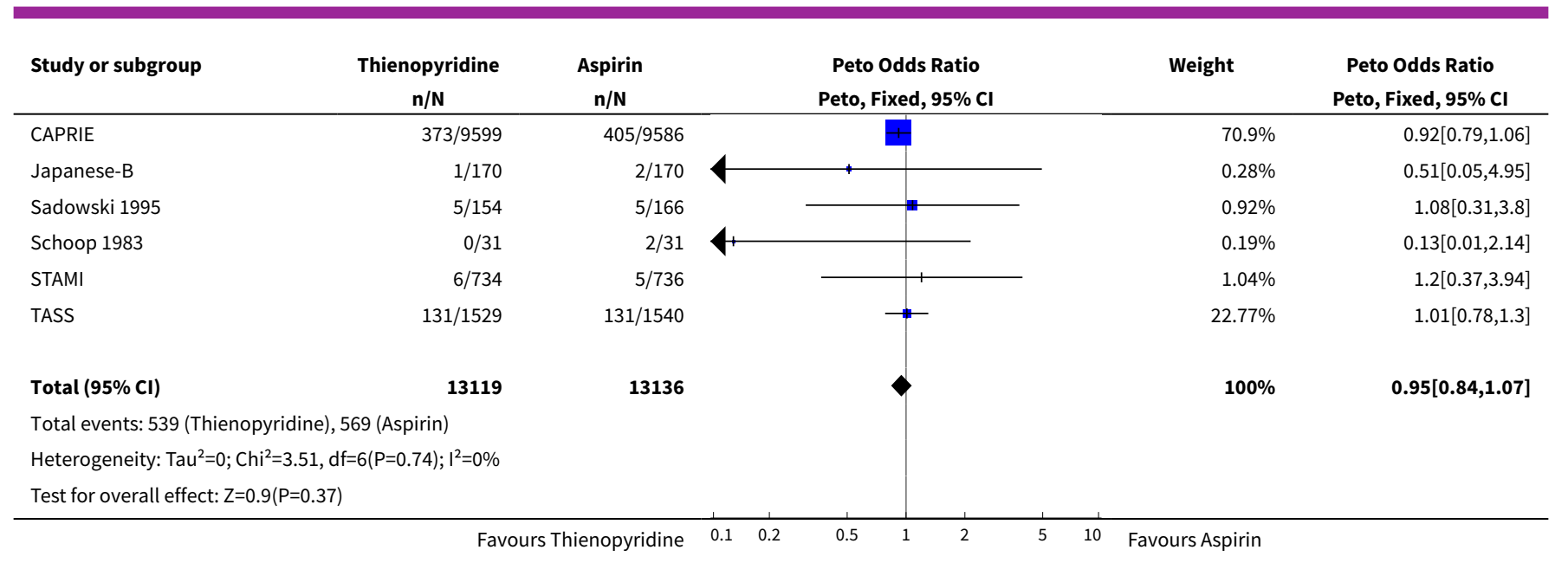

Analysis 1.8. Comparison 1 Thienopyridine versus aspirin in high vascular risk patients, Outcome 8 Death from any cause during follow up.

\begin{tabular}{|c|c|c|c|c|c|}
\hline Study or subgroup & $\begin{array}{c}\text { Thienopyridine } \\
\mathrm{n} / \mathrm{N} \\
\end{array}$ & $\begin{array}{c}\text { Aspirin } \\
\mathrm{n} / \mathrm{N}\end{array}$ & $\begin{array}{c}\text { Peto Odds Ratio } \\
\text { Peto, Fixed, 95\% Cl }\end{array}$ & Weight & $\begin{array}{c}\text { Peto Odds Ratio } \\
\text { Peto, Fixed, 95\% Cl }\end{array}$ \\
\hline AAASPS & $45 / 902$ & $40 / 907$ & +1 & $5.4 \%$ & $1.14[0.74,1.76]$ \\
\hline CAPRIE & $560 / 9599$ & $571 / 9586$ & & $70.91 \%$ & $0.98[0.87,1.1]$ \\
\hline Japanese-B & $1 / 170$ & $2 / 170$ & & $0.2 \%$ & $0.51[0.05,4.95]$ \\
\hline Sadowski 1995 & $5 / 154$ & $5 / 166$ & & $0.65 \%$ & $1.08[0.31,3.8]$ \\
\hline Schoop 1983 & $0 / 31$ & $5 / 31$ & & $0.31 \%$ & $0.12[0.02,0.72]$ \\
\hline STAMI & $7 / 734$ & $5 / 736$ & & $0.79 \%$ & $1.4[0.45,4.37]$ \\
\hline TASS & $175 / 1529$ & $196 / 1540$ & $\rightarrow$ & $21.74 \%$ & $0.89[0.71,1.1]$ \\
\hline Total $(95 \% \mathrm{Cl})$ & 13119 & 13136 & 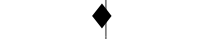 & $100 \%$ & $0.96[0.87,1.06]$ \\
\hline \multicolumn{6}{|c|}{ Total events: 793 (Thienopyridine), 824 (Aspirin) } \\
\hline \multicolumn{6}{|c|}{ Heterogeneity: $\mathrm{Tau}^{2}=0 ; \mathrm{Chi}^{2}=7.1, \mathrm{df}=6(\mathrm{P}=0.31) ; \mathrm{I}^{2}=15.54 \%$} \\
\hline Test for overall effec & & & & & \\
\hline
\end{tabular}

Analysis 1.9. Comparison 1 Thienopyridine versus aspirin in high vascular risk patients, Outcome 9 Extracranial haemorrhage during follow up.

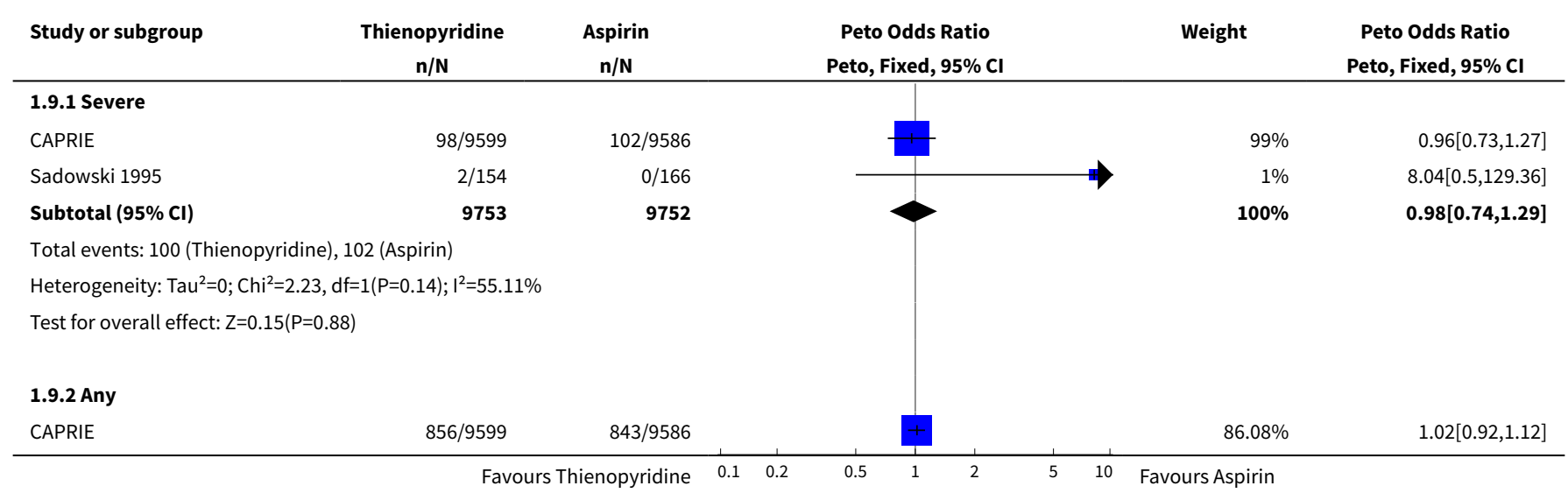




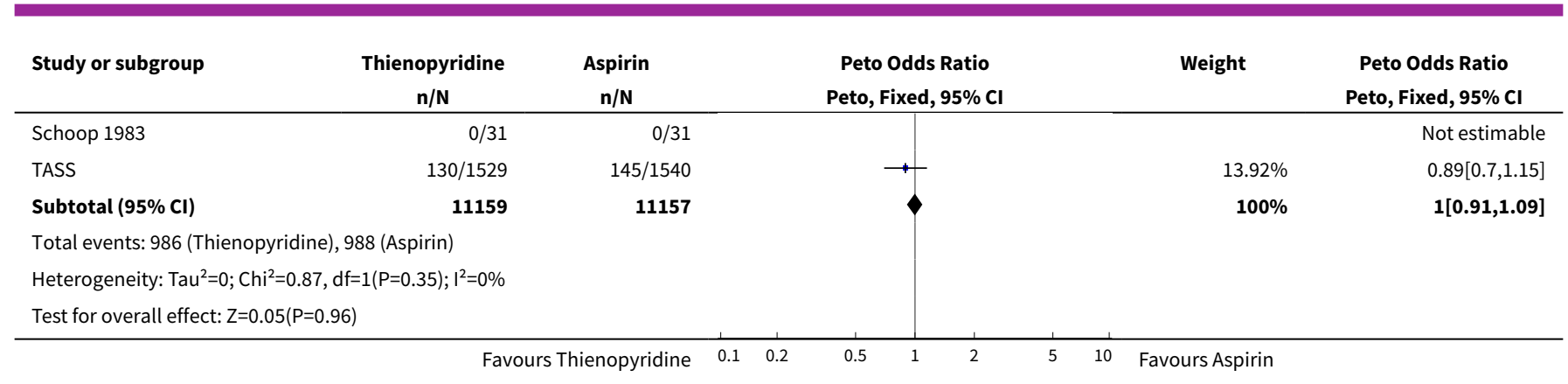

Analysis 1.10. Comparison 1 Thienopyridine versus aspirin in high vascular risk patients, Outcome 10 Gastrointestinal haemorrhage during follow up.

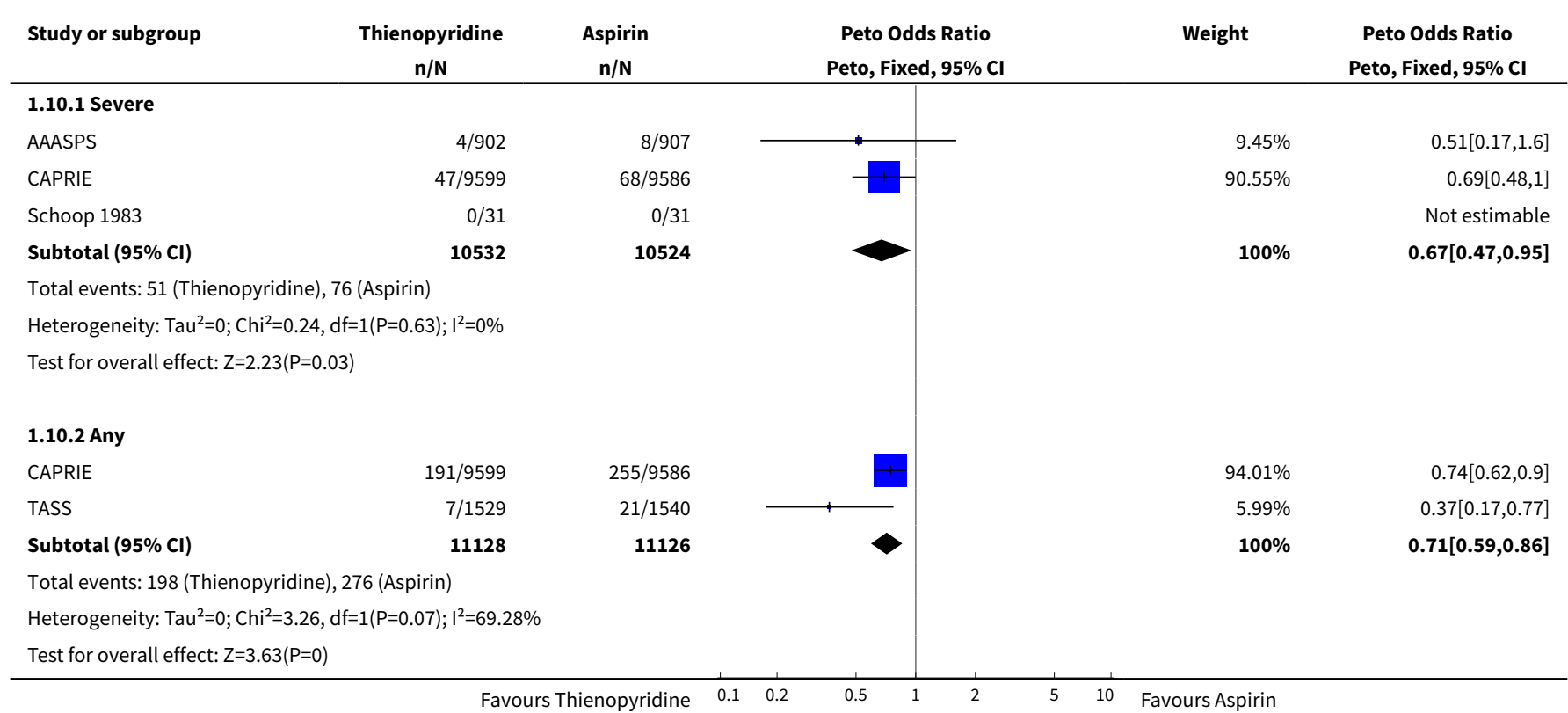

Analysis 1.11. Comparison 1 Thienopyridine versus aspirin in high vascular risk patients, Outcome 11 Indigestion/nausea/vomiting during follow up.

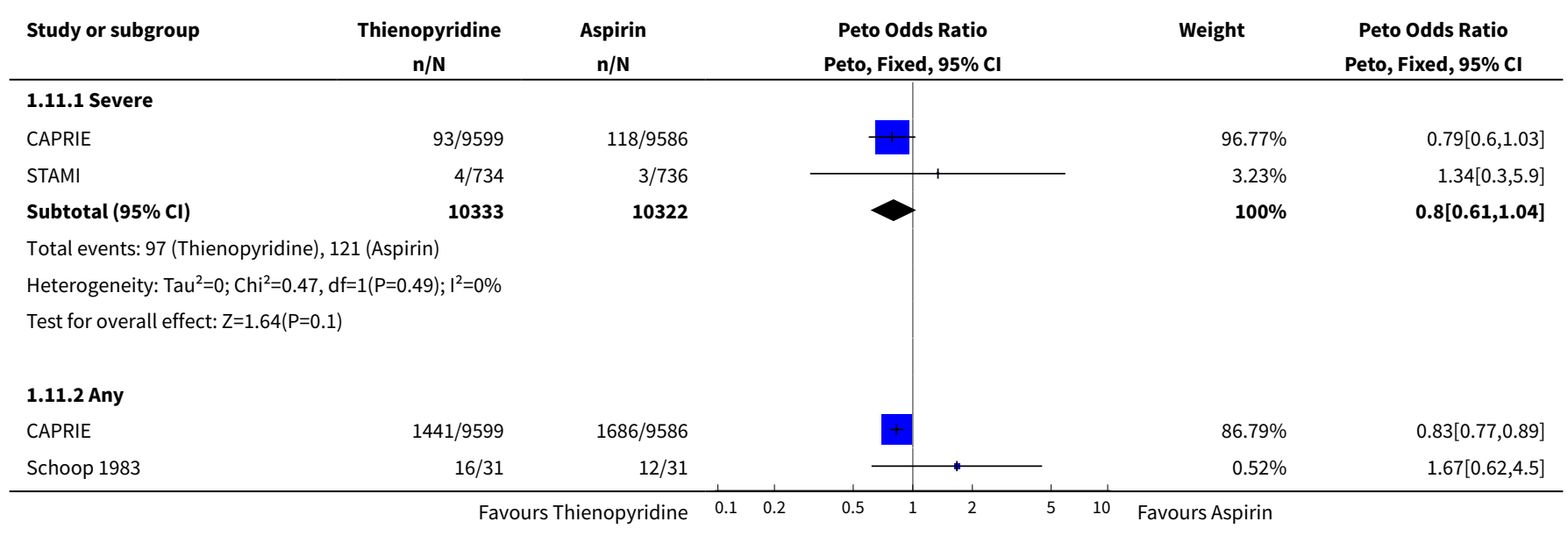




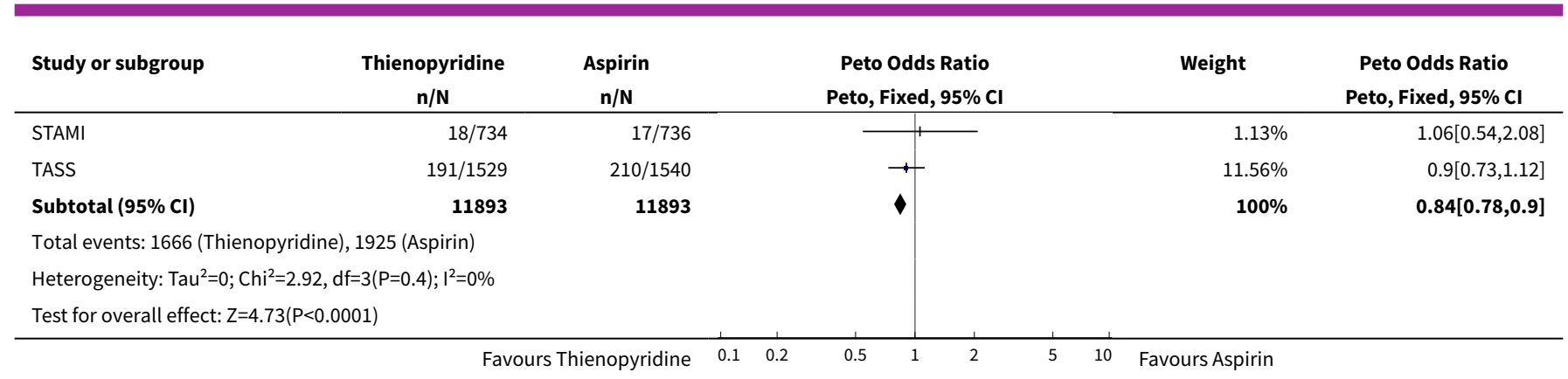

Analysis 1.12. Comparison 1 Thienopyridine versus aspirin in high vascular risk patients, Outcome 12 Neutropenia during follow up.

\begin{tabular}{|c|c|c|c|c|c|}
\hline Study or subgroup & $\begin{array}{c}\text { Thienopyridine } \\
\mathrm{n} / \mathrm{N} \\
\end{array}$ & $\begin{array}{c}\text { Aspirin } \\
\mathrm{n} / \mathrm{N}\end{array}$ & $\begin{array}{c}\text { Peto Odds Ratio } \\
\text { Peto, Fixed, } 95 \% \mathrm{Cl}\end{array}$ & Weight & $\begin{array}{c}\text { Peto Odds Ratio } \\
\text { Peto, Fixed, 95\% Cl }\end{array}$ \\
\hline \multicolumn{6}{|l|}{ 1.12.1 Severe } \\
\hline AAASPS & $31 / 902$ & $20 / 907$ & & $69.32 \%$ & $1.57[0.9,2.73]$ \\
\hline CAPRIE & $5 / 9599$ & $4 / 9586$ & & $12.58 \%$ & $1.25[0.34,4.61]$ \\
\hline TASS & $13 / 1529$ & $0 / 1540$ & & $18.1 \%$ & $7.5[2.52,22.3]$ \\
\hline Subtotal $(95 \% \mathrm{CI})$ & 12030 & 12033 & & $100 \%$ & $2.02[1.27,3.21]$ \\
\hline \multicolumn{6}{|c|}{ Total events: 49 (Thienopyridine), 24 (Aspirin) } \\
\hline \multicolumn{6}{|c|}{ Heterogeneity: $\mathrm{Tau}^{2}=0 ; \mathrm{Chi}^{2}=6.89, \mathrm{df}=2(\mathrm{P}=0.03) ; \mathrm{I}^{2}=70.99 \%$} \\
\hline \multicolumn{6}{|c|}{ Test for overall effect: $Z=2.98(P=0)$} \\
\hline \multicolumn{6}{|l|}{ 1.12.2 Any } \\
\hline CAPRIE & $10 / 9599$ & $16 / 9586$ & \begin{tabular}{l|l}
$\mathbf{m}$ & \\
$\mathbf{m}$
\end{tabular} & $35.93 \%$ & $0.63[0.29,1.36]$ \\
\hline TASS & $35 / 1529$ & $12 / 1540$ & & $64.07 \%$ & $2.72[1.53,4.84]$ \\
\hline \multicolumn{6}{|c|}{ Total events: 45 (Thienopyridine), 28 (Aspirin) } \\
\hline \multicolumn{6}{|c|}{ Heterogeneity: $\mathrm{Tau}^{2}=0 ; \mathrm{Chi}^{2}=8.92, \mathrm{df}=1(\mathrm{P}=0) ; \mathrm{I}^{2}=88.79 \%$} \\
\hline Test for overall effect & & & & & \\
\hline
\end{tabular}

Analysis 1.13. Comparison 1 Thienopyridine versus aspirin in high vascular risk patients, Outcome 13 Any neutropenia (thienopyridine subgroups).

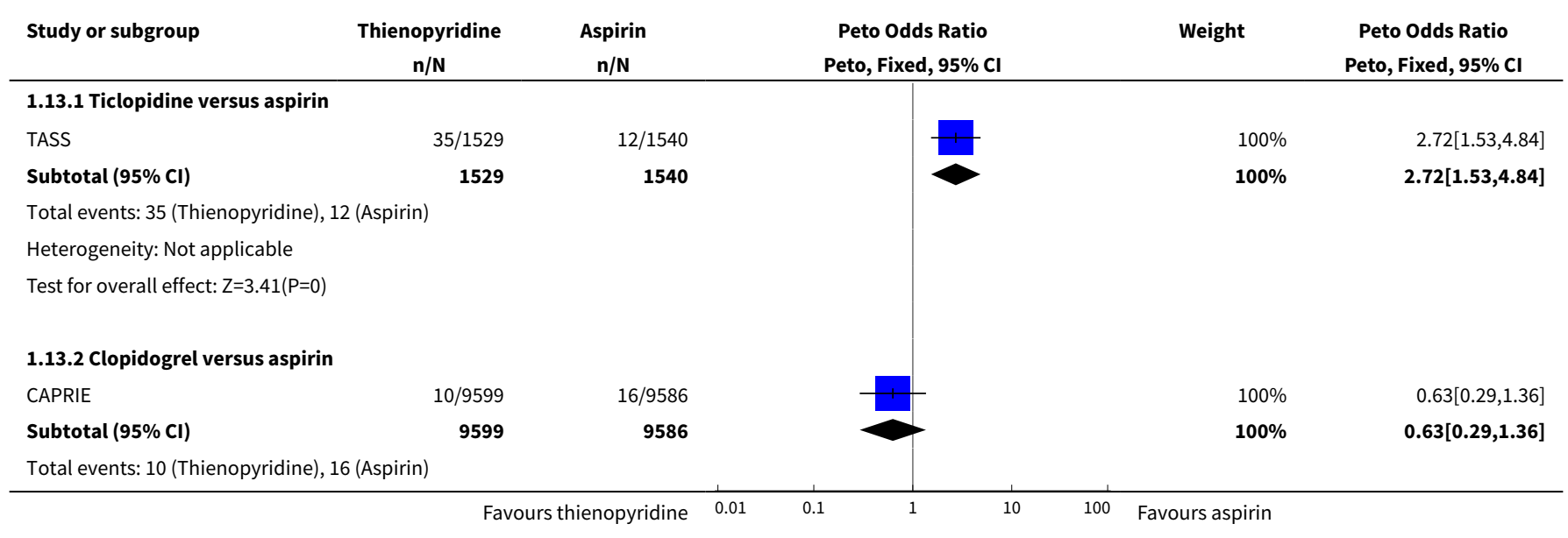




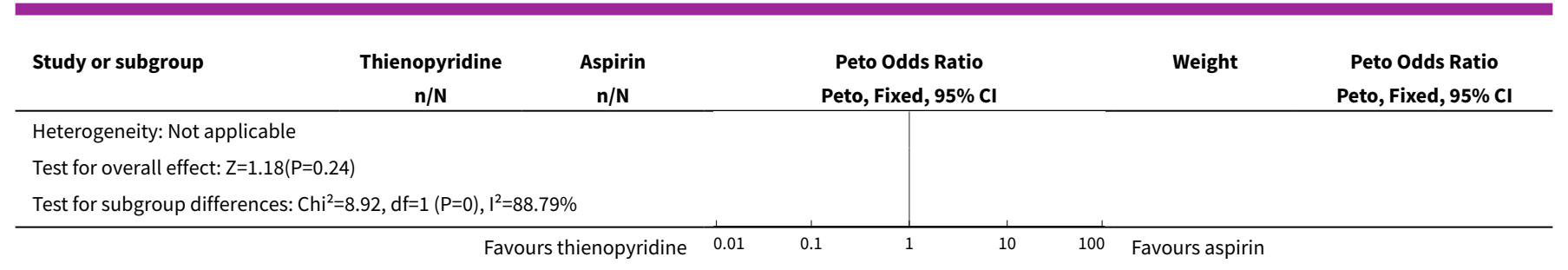

Analysis 1.14. Comparison 1 Thienopyridine versus aspirin in high vascular risk patients, Outcome 14 Thrombocytopenia during follow up.

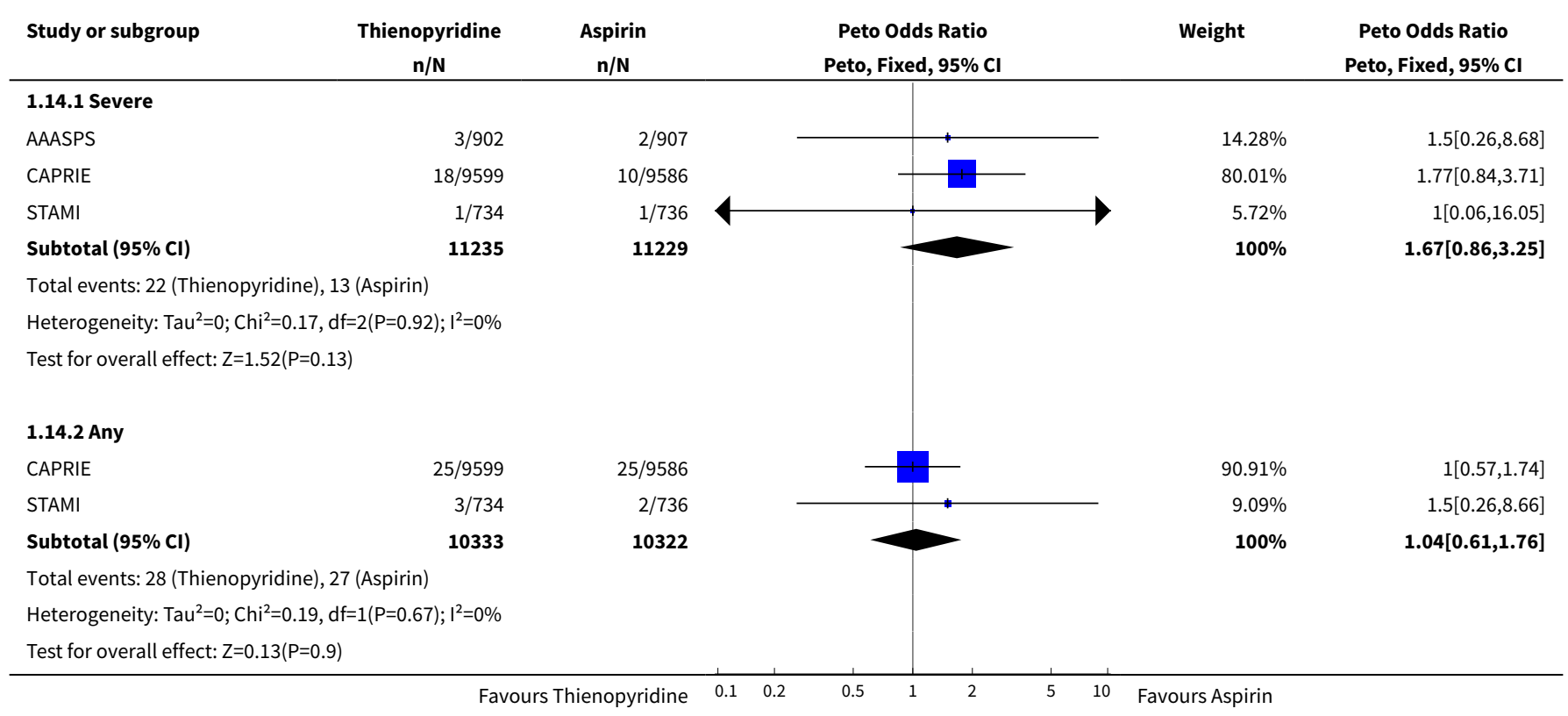

Analysis 1.15. Comparison 1 Thienopyridine versus aspirin in high vascular risk patients, Outcome 15 Any thrombocytopenia (thienopyridine subgroups).

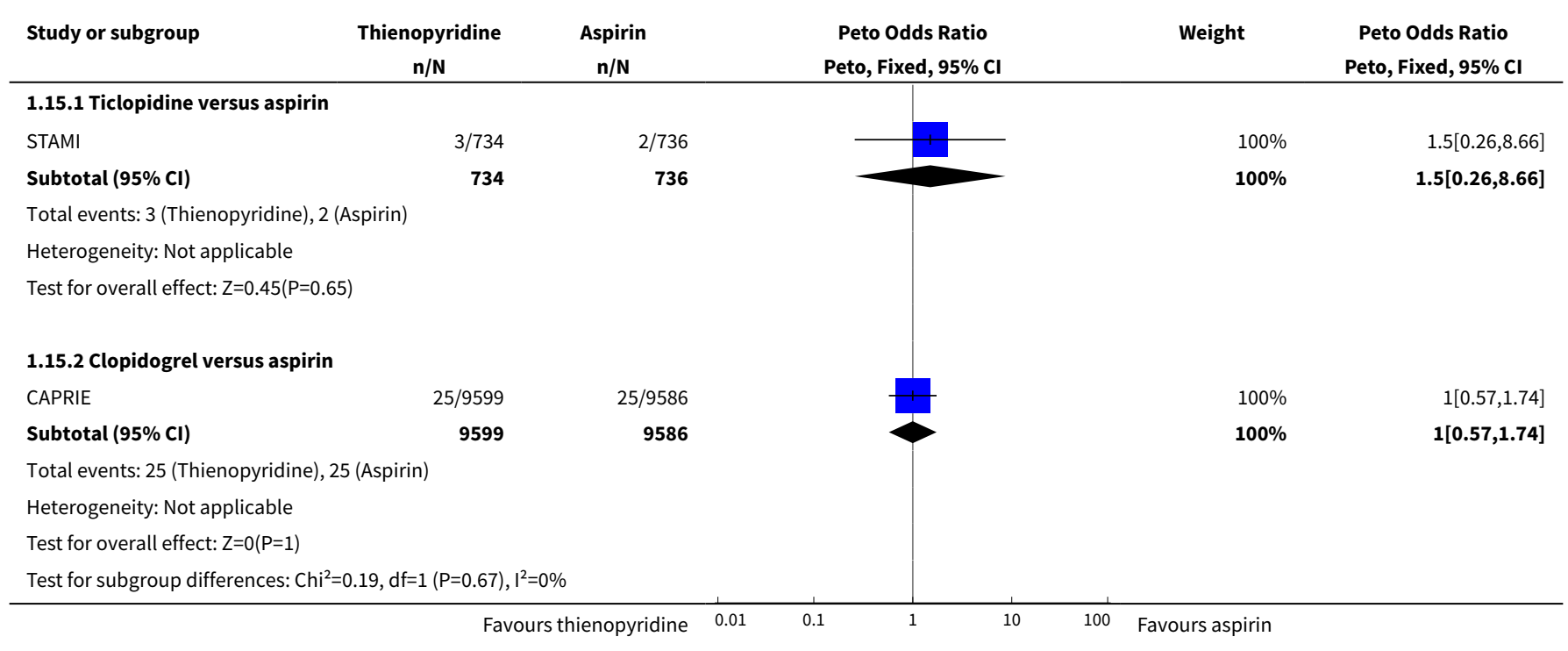




\section{Analysis 1.16. Comparison 1 Thienopyridine versus aspirin in high vascular risk patients, Outcome 16 Skin rash during follow up.}

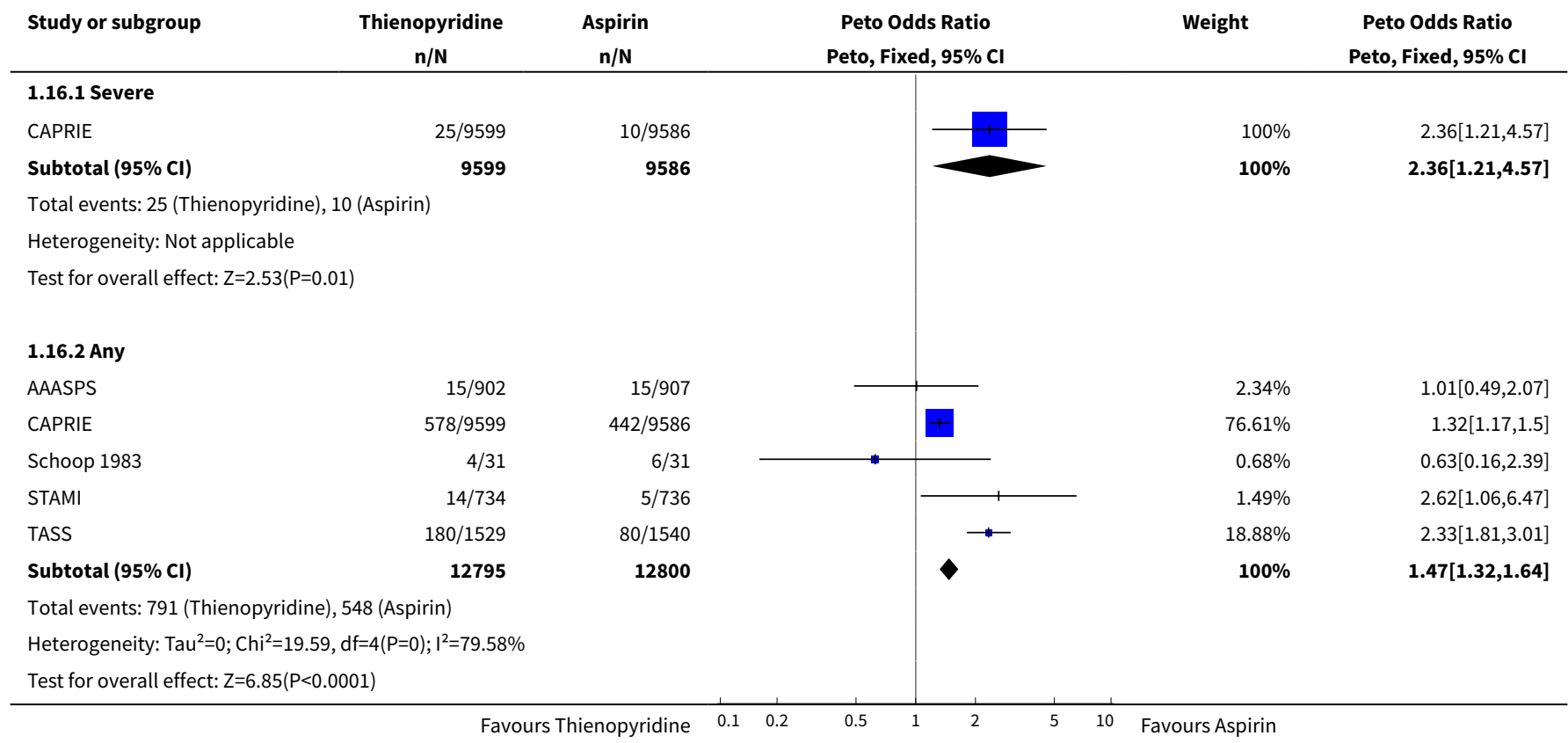

\section{Analysis 1.17. Comparison 1 Thienopyridine versus aspirin in high vascular risk patients, Outcome 17 Any skin rash (thienopyridine subgroups).}

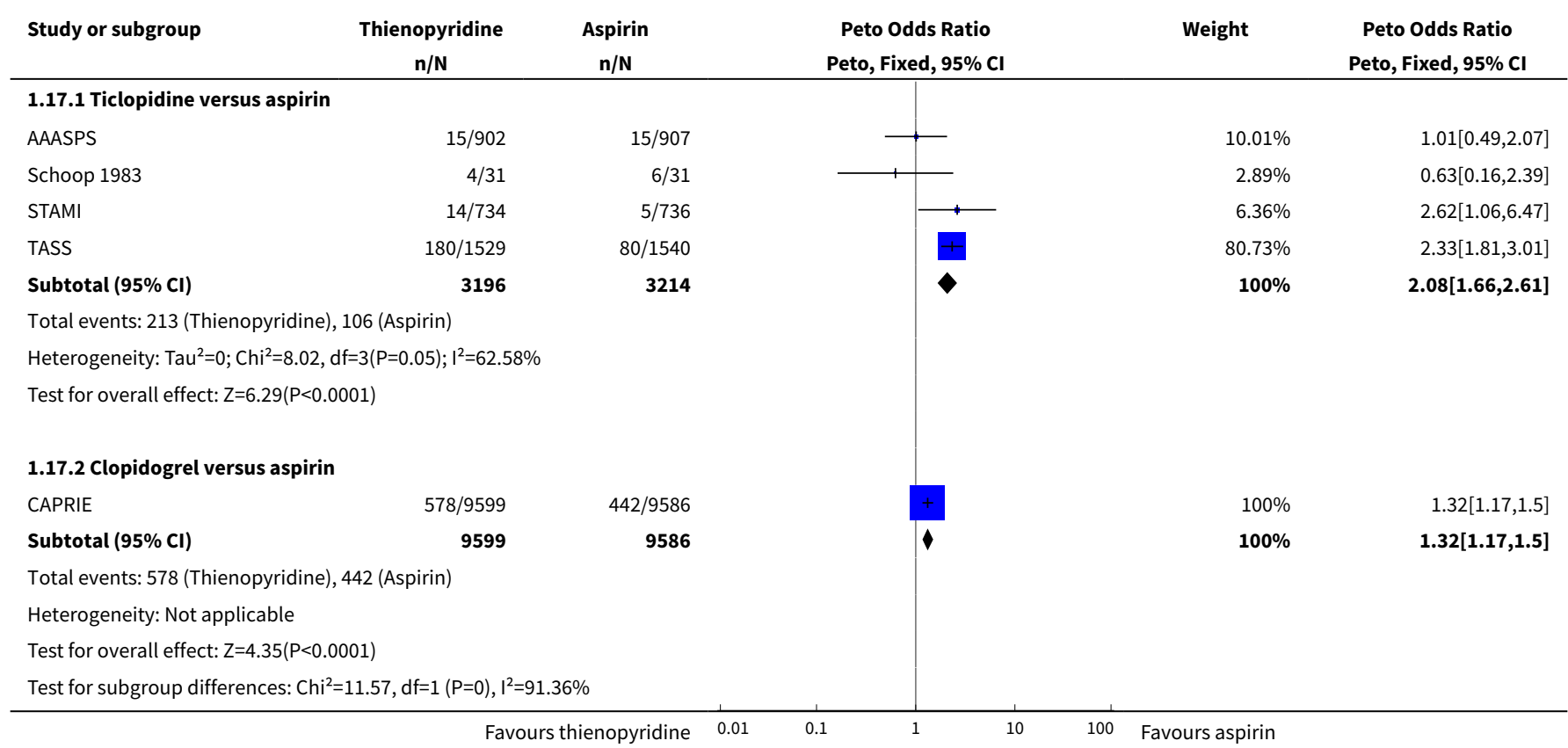

Thienopyridine derivatives versus aspirin for preventing stroke and other serious vascular events in high vascular risk patients (Review) 
Analysis 1.18. Comparison 1 Thienopyridine versus aspirin in high vascular risk patients, Outcome 18 Diarrhoea during follow up.

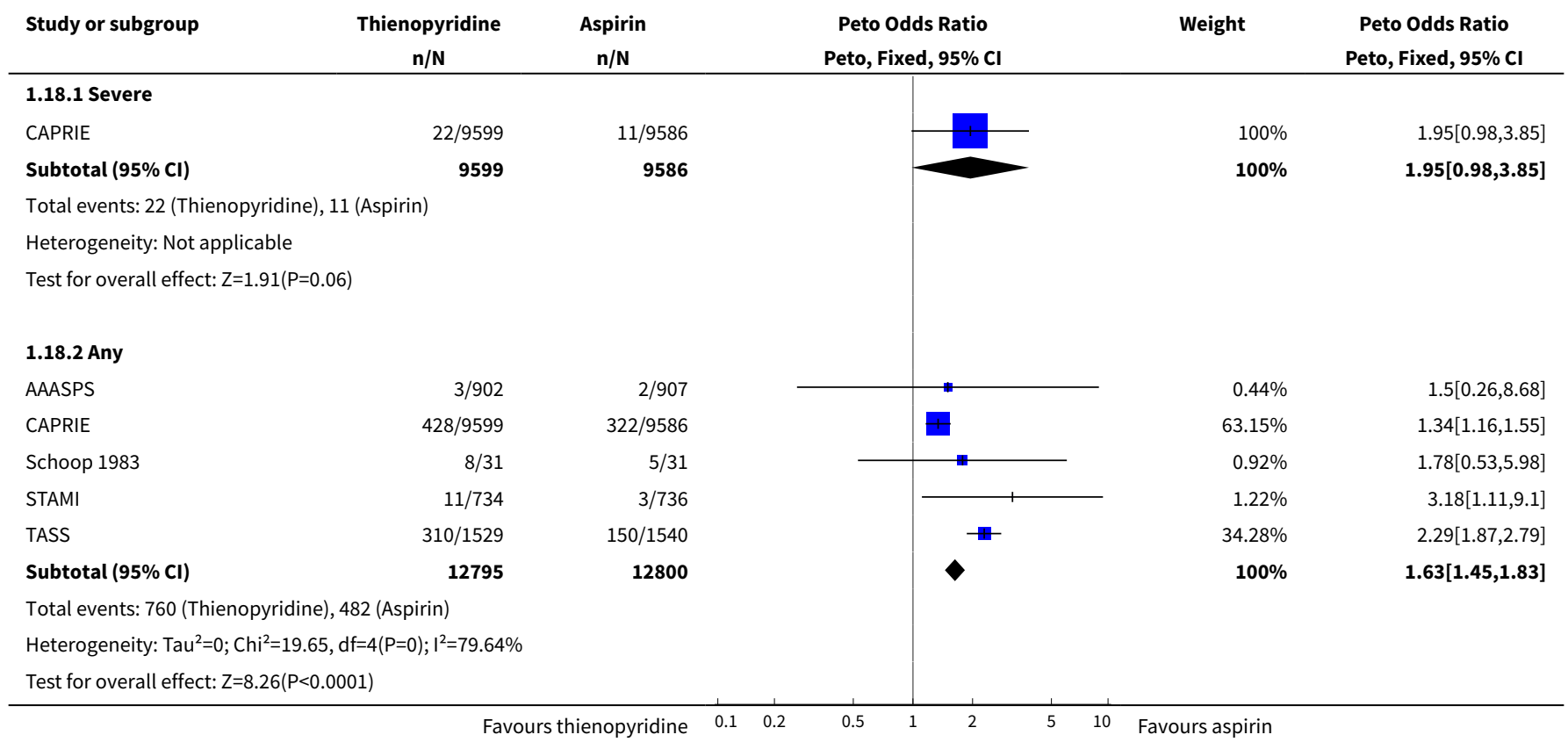

\section{Analysis 1.19. Comparison 1 Thienopyridine versus aspirin in high vascular risk patients, Outcome 19 Any diarrhoea (thienopyridine subgroups).}

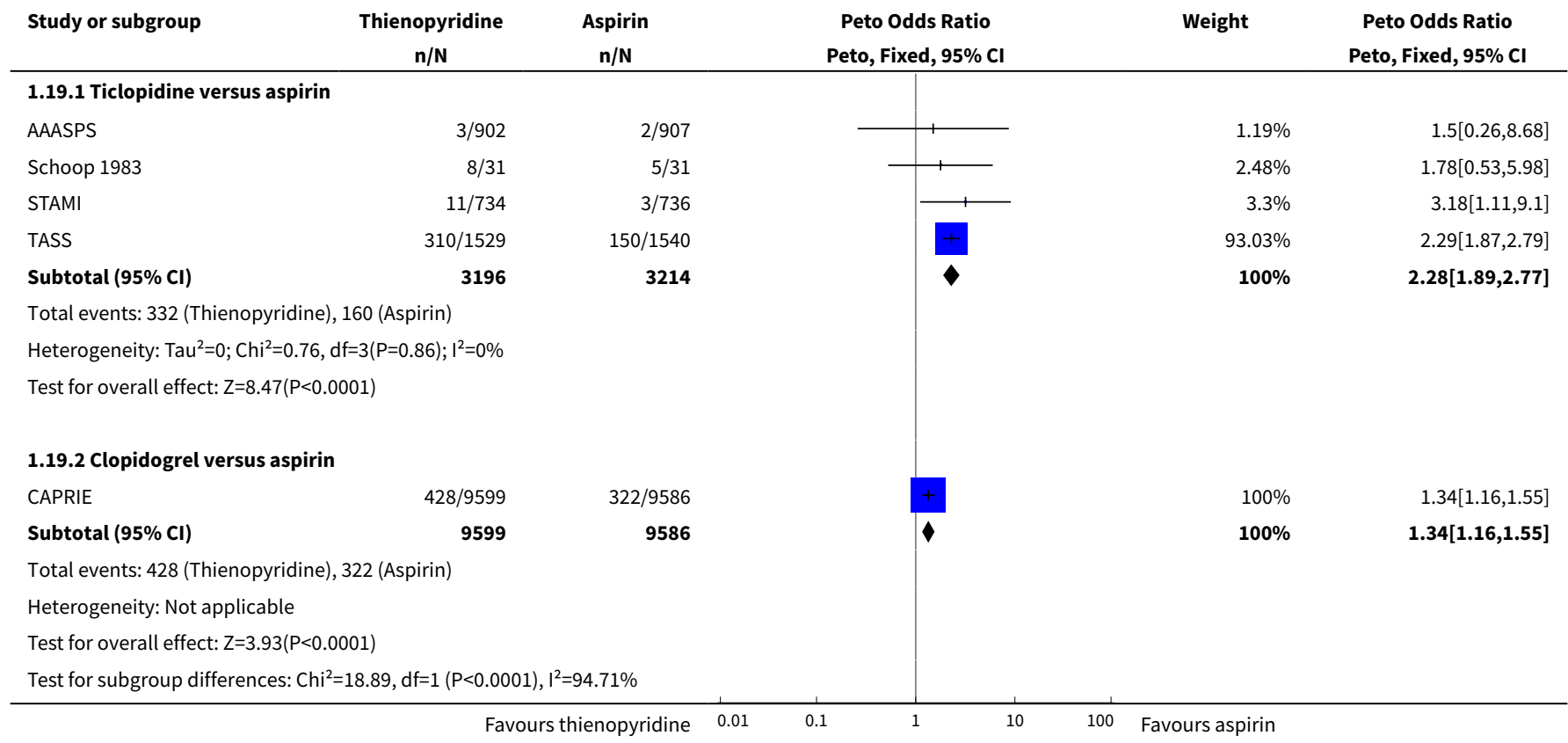

Thienopyridine derivatives versus aspirin for preventing stroke and other serious vascular events in high vascular risk patients (Review) 
Comparison 2. Thienopyridine versus aspirin in patients with TIA or ischaemic stroke

\begin{tabular}{|c|c|c|c|c|}
\hline Outcome or subgroup title & $\begin{array}{l}\text { No. of } \\
\text { studies }\end{array}$ & $\begin{array}{l}\text { No. of } \\
\text { partici- } \\
\text { pants }\end{array}$ & Statistical method & Effect size \\
\hline $\begin{array}{l}1 \text { Stroke, MI, or vascular death during fol- } \\
\text { low up }\end{array}$ & 4 & 11649 & Peto Odds Ratio (Peto, Fixed, $95 \% \mathrm{Cl}$ ) & $0.94[0.85,1.03]$ \\
\hline $\begin{array}{l}2 \text { Ischaemic/unknown stroke during follow } \\
\text { up }\end{array}$ & 3 & 9829 & Peto Odds Ratio (Peto, Fixed, 95\% Cl) & $0.85[0.75,0.97]$ \\
\hline 3 Stroke (of all types) during follow up & 5 & 11978 & Peto Odds Ratio (Peto, Fixed, $95 \% \mathrm{Cl}$ ) & $0.90[0.80,1.00]$ \\
\hline $\begin{array}{l}4 \text { Haemorrhagic stroke (symptomatic in- } \\
\text { tracranial haemorrhage) during follow up }\end{array}$ & 3 & 9829 & Peto Odds Ratio (Peto, Fixed, $95 \% \mathrm{Cl}$ ) & $0.96[0.60,1.55]$ \\
\hline
\end{tabular}

Analysis 2.1. Comparison 2 Thienopyridine versus aspirin in patients with TIA or ischaemic stroke, Outcome 1 Stroke, MI, or vascular death during follow up.

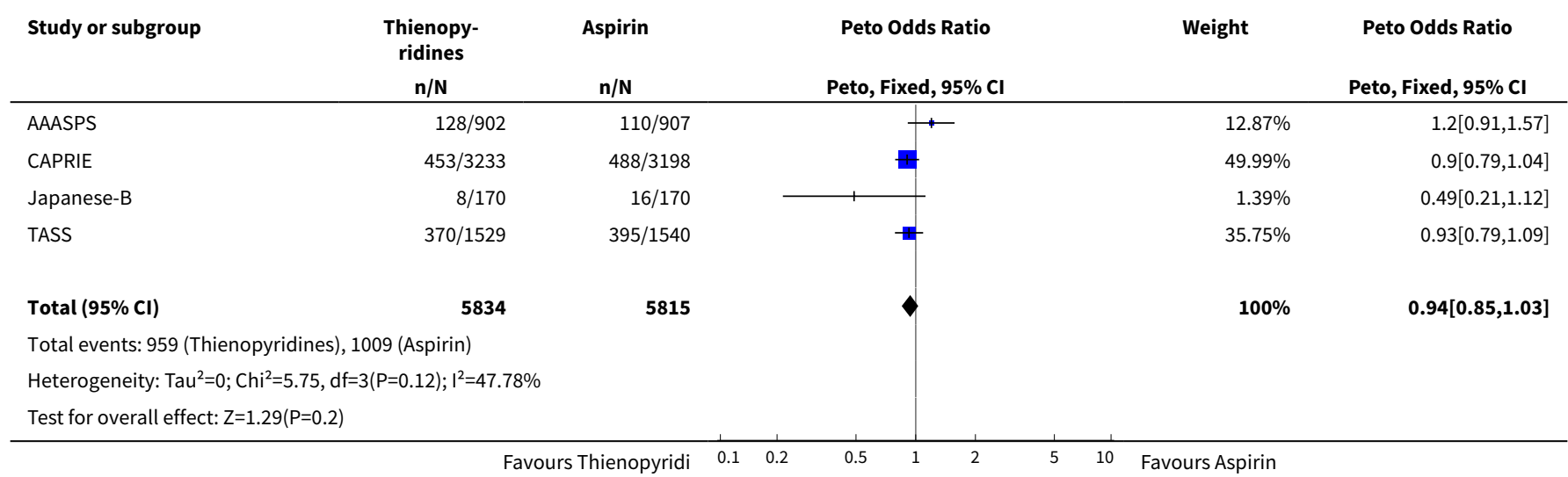

Analysis 2.2. Comparison 2 Thienopyridine versus aspirin in patients with TIA or ischaemic stroke, Outcome 2 Ischaemic/unknown stroke during follow up.

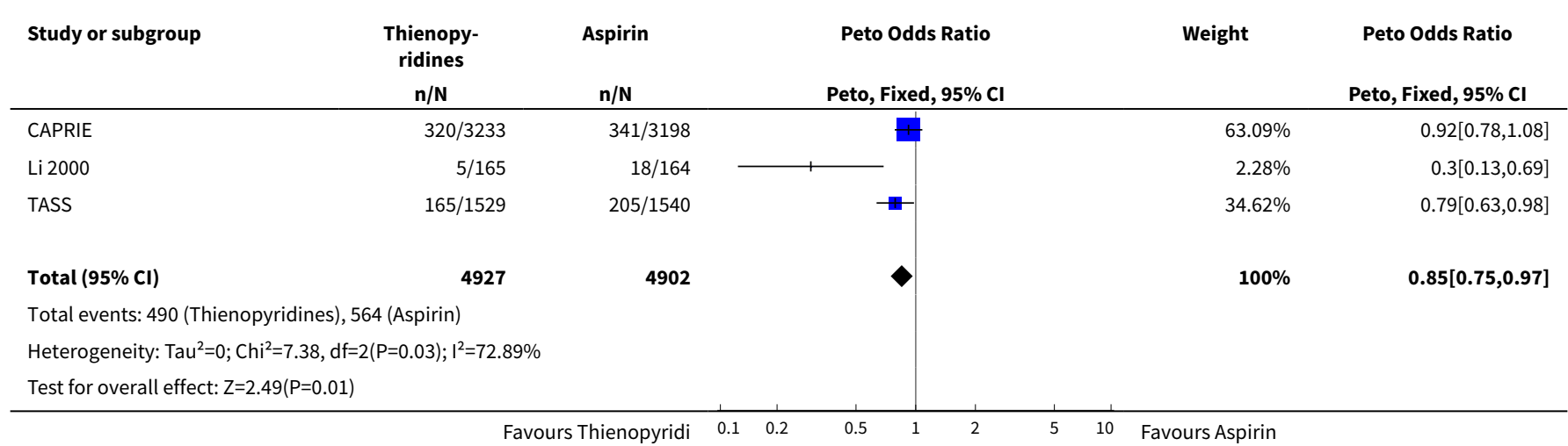


Analysis 2.3. Comparison 2 Thienopyridine versus aspirin in patients with TIA or ischaemic stroke, Outcome 3 Stroke (of all types) during follow up.

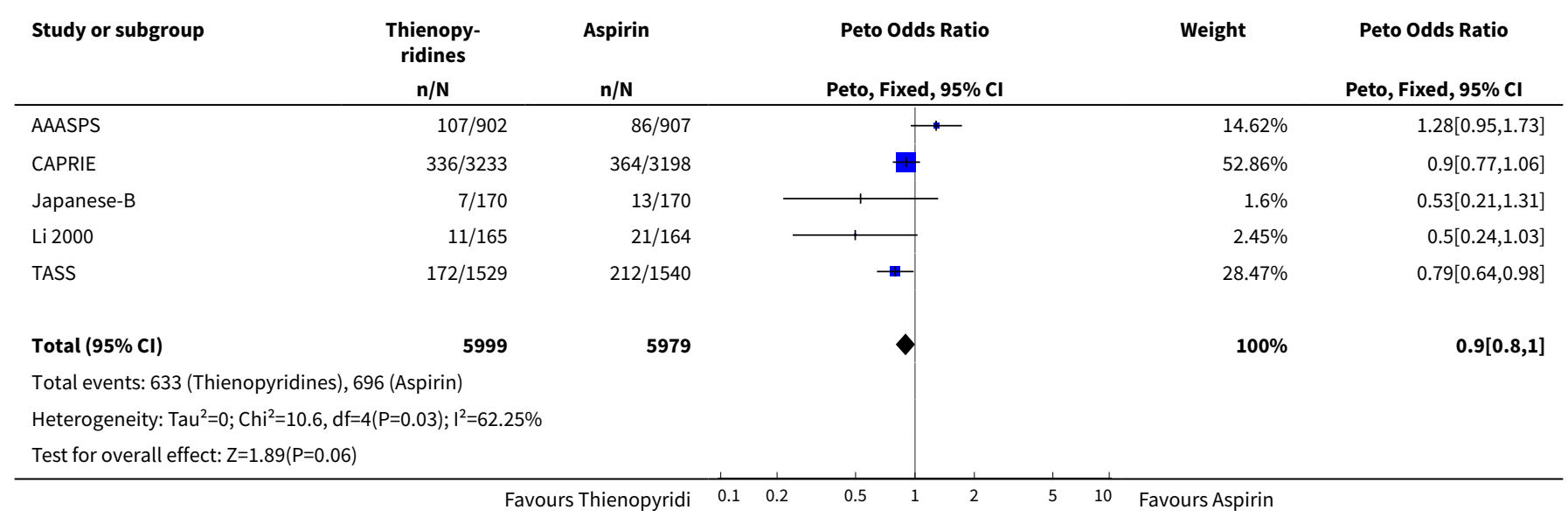

Analysis 2.4. Comparison 2 Thienopyridine versus aspirin in patients with TIA or ischaemic stroke, Outcome 4 Haemorrhagic stroke (symptomatic intracranial haemorrhage) during follow up.

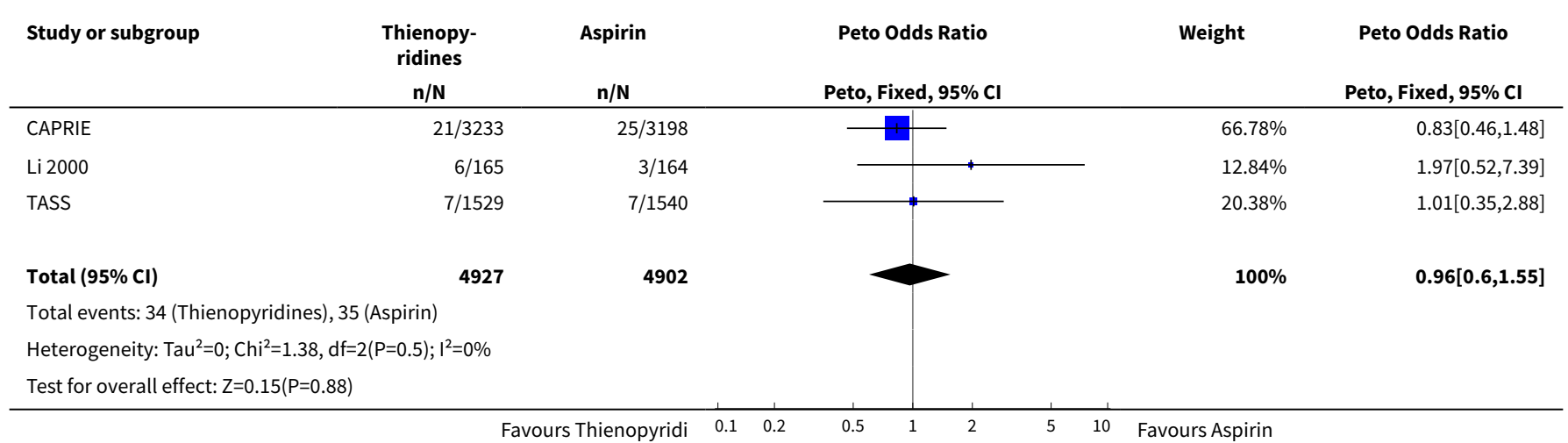

Comparison 3. Thienopyridine versus aspirin in high vascular risk patients - sensitivity analysis

\begin{tabular}{lllll}
\hline Outcome or subgroup title & $\begin{array}{l}\text { No. of } \\
\text { studies }\end{array}$ & $\begin{array}{l}\text { No. of par- } \\
\text { ticipants }\end{array}$ & Statistical method & Effect size \\
\hline $\begin{array}{l}\text { 1 Serious vascular events (sensible worst case } \\
\text { scenario) }\end{array}$ & 7 & 26255 & $\begin{array}{l}\text { Peto Odds Ratio (Peto, Fixed, 95\% } \\
\text { Cl) }\end{array}$ & 0.92 [0.86, 0.99] \\
\hline
\end{tabular}

Analysis 3.1. Comparison 3 Thienopyridine versus aspirin in high vascular risk patients - sensitivity analysis, Outcome 1 Serious vascular events (sensible worst case scenario).

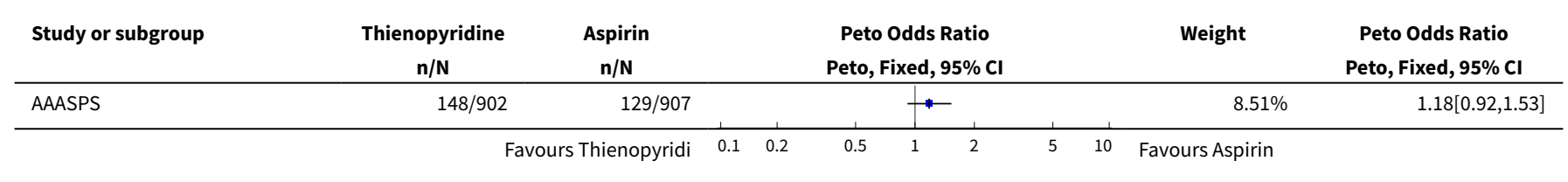




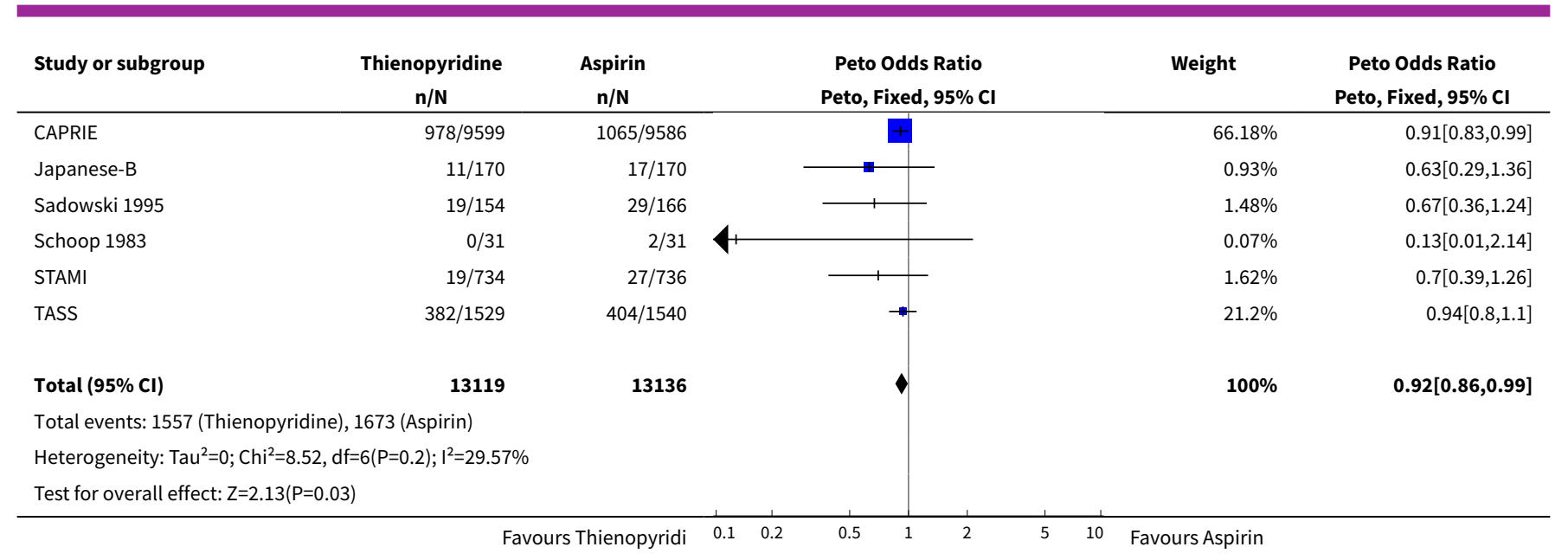

\section{APPENDICES}

\section{Appendix 1. MEDLINE search strategy}

We used the following search strategy for MEDLINE (Ovid) and adapted it for CENTRAL

1. ticlopidine/

2. (ticlopidine or ticlid or tiklid or tiklyd or ticlodix or ticlodone or ticlodine or anagregal or panaldine).tw.

3. (clopidogrel or plavix or iscover).tw.

4. thienopyridine\$.tw.

5. ((adenosine diphosphate or adp) adj5 receptor adj5 antagonist\$).tw.

6.1 or 2 or 3 or 4 or 5

7. aspirin/

8. (aspirin or acetylsalicylic acid or acetyl salicylic acid).tw.

9.7 or 8

10. Randomized Controlled Trials as Topic/

11. random allocation/

12. Controlled Clinical Trials as Topic/

13. control groups/

14. clinical trials as topic/ or clinical trials, phase i as topic/ or clinical trials, phase ii as topic/ or clinical trials, phase iii as topic/ or clinical trials, phase iv as topic/

15. Clinical Trials Data Monitoring Committees/

16. double-blind method/

17. single-blind method/

18. Placebos/

19. placebo effect/

20. Drug Evaluation/

21. Research Design/

22. randomized controlled trial.pt.

23. controlled clinical trial.pt.

24. (clinical trial or clinical trial phase i or clinical trial phase ii or clinical trial phase iii or clinical trial phase iv).pt.

25. meta analysis.pt.

26. meta-analysis as topic/

27. random\$.tw.

28. (controlled adj5 (trial\$ or stud\$)).tw.

29. (clinical\$ adj5 trial\$).tw.

30. ((control or treatment or experiment $\$$ or intervention) adj5 (group\$ or subject\$ or patient\$)).tw.

31. (quasi-random $\$$ or quasi random $\$$ or pseudo-random $\$$ or pseudo random $\$$ ).tw.

32. ((control or experiment $\$$ or conservative) adj5 (treatment or therapy or procedure or manage $\$)) . t w$.

33. ((singl\$ or doubl\$ or tripl\$ or trebl\$) adj5 (blind\$ or mask\$)).tw.

34. (coin adj5 (flip or flipped or toss\$)).tw.

35. latin square.tw.

Thienopyridine derivatives versus aspirin for preventing stroke and other serious vascular events in high vascular risk patients (Review) 
36. (aspirin versus or versus aspirin).tw.

37. placebo\$.tw.

38. (assign\$ or alternate or allocat\$ or counterbalance or multiple baseline).tw.

39. (meta-analy\$ or metaanaly $\$$ or meta analy\$ or systematic review or systematic overview).tw.

40. or/10-39

41.6 and 9 and 40

42. limit 41 to human

\section{Appendix 2. EMBASE search strategy}

We used the following search strategy for EMBASE (Ovid)

1. ticlopidine/

2. (ticlopidine or ticlid or tiklid or tiklyd or ticlodix or ticlodone or ticlodine or anagregal or panaldine).tw.

3. clopidogrel/

4. (clopidogrel or plavix or iscover).tw.

5. thienopyridine $\$$.tw.

6. ((adenosine diphosphate or adp) adj5 receptor adj5 antagonist\$).tw.

7. 1 or 2 or 3 or 4 or 5 or 6

8. acetylsalicylic acid/

9. (aspirin or acetylsalicylic acid or acetyl salicylic acid).tw.

10.8 or 9

11. Randomized Controlled Trial/

12. Randomization/

13. Controlled Study/

14. control group/

15. exp Clinical Trial/

16. Double Blind Procedure/

17. Single Blind Procedure/

18. latin square design/

19. Parallel Design/

20. drug comparison/

21. "types of study"/

22. "systematic review"/

23. Meta Analysis/

24. random\$.tw.

25. (controlled adj5 (trial\$ or stud\$)).tw.

26. (clinical\$ adj5 trial\$).tw.

27. ((control or treatment or experiment\$ or intervention) adj5 (group\$ or subject\$ or patient\$)).tw.

28. (quasi-random\$ or quasi random\$ or pseudo-random\$ or pseudo random\$).tw.

29. ((control or experiment\$ or conservative) adj5 (treatment or therapy)).tw.

30. ((singl\$ or doubl\$ or tripl\$ or trebl\$) adj5 (blind\$ or mask\$)).tw.

31. (coin adj5 (flip or flipped or toss\$)).tw.

32. latin square.tw.

33. (meta-analy\$ or metaanaly\$ or meta analy\$ or systematic review or systematic overview).tw.

34. (assign\$ or allocate\$).tw.

35. (aspirin versus or versus aspirin).tw.

36. or/11-35

37.7 and 10 and 36

38. limit 37 to human

WHAT'S NEW

\begin{tabular}{lll}
\hline Date & Event & Description \\
\hline 9 July 2009 & New search has been performed & $\begin{array}{l}\text { The review has been updated to include six new trials involving } \\
4209 \text { participants, bringing the total number of included trials } \\
\end{array}$ \\
& to 10 involving 26,865 participants. The Background and Discus- \\
& sion sections have been updated to include new material of rele-
\end{tabular}

Thienopyridine derivatives versus aspirin for preventing stroke and other serious vascular events in high vascular risk patients (Review) 36 Copyright $\odot 2010$ The Cochrane Collaboration. Published by John Wiley \& Sons, Ltd. 


\begin{tabular}{lll}
\hline Date & Event & Description \\
\hline & $\begin{array}{l}\text { vance. The main conclusions are essentially unchanged from the } \\
\text { previous version of the review. }\end{array}$ \\
\hline 9 July 2009 & $\begin{array}{l}\text { New citation required but conclusions } \\
\text { have not changed }\end{array}$ & The authorship of the review has changed. \\
\hline
\end{tabular}

\section{HISTORY}

Protocol first published: Issue 4, 1998

Review first published: Issue 1, 2000

\begin{tabular}{lll}
\hline Date & Event & Description \\
\hline 18 August 2008 & Amended & Converted to new review format. \\
\hline
\end{tabular}

\section{CONTRIBUTIONS OFAUTHORS}

Dr Cathie Sudlow is the guarantor of this version of the review and supervised and participated in all aspects of its development, including searching for studies, study selection, data extraction, analysis, interpretation and writing of the review.

Dr Gillian Mason performed update searches for this version of the review, selected studies, extracted data from new studies, performed analyses and assisted with writing the review.

Catherine Wedderburn and James Maurice performed update searches for this version of the review, selected studies for inclusion and exclusion, and assisted with writing the review.

Prof Graeme Hankey co-ordinated searches, study selection, data extraction, analysis and writing of the previous version of this review, and assisted with writing the current version.

\section{DECLARATIONS OF INTEREST}

Prof Graeme Hankey has received honoraria for lecturing at scientific symposia sponsored by Sanofi Aventis, Bristol Meyers Squibb, and Boehringer Ingelheim, and has received fees for consulting from Sanofi Aventis, Bristol Meyers Squibb, and Boehringer Ingelheim.

\section{SOURCES OF SUPPORT}

\section{Internal sources}

- Royal Perth Hospital Clinical Staff Education Fund, Australia.

\section{External sources}

- Wellcome Trust, UK.

\section{IN DEX TERMS}

\section{Medical Subject Headings (MeSH)}

Aspirin [ ${ }^{*}$ therapeutic use]; Cardiovascular Diseases [ ${ }^{*}$ prevention \& control]; Clopidogrel; Myocardial Infarction [prevention \& control]; Platelet Aggregation Inhibitors [ ${ }^{\star}$ therapeutic use]; Randomized Controlled Trials as Topic; Stroke [prevention \& control]; Ticlopidine [analogs \& derivatives] [*therapeutic use]

\section{MeSH check words}

Humans 